(C) 2020, The Authors. Published by Elsevier Inc. and Fass Inc. on behalf of the American Dairy Science Association ${ }^{\circledR}$. This is an open access article under the CC BY-NC-ND license (http://creativecommons.org/licenses/by-nc-nd/4.0/).

\title{
Modeling fatty acids for dairy cattle: Models to predict total fatty acid concentration and fatty acid digestion of feedstuffs
}

\author{
V. L. Daley, ${ }^{1,2} \oplus$ L. E. Armentano, ${ }^{3} \oplus$ P. J. Kononoff, ${ }^{4}{ }^{\oplus}$ and M. D. Hanigan ${ }^{2 *} \oplus$ \\ ${ }^{1}$ National Animal Nutrition Program, Department of Animal and Food Sciences, University of Kentucky, Lexington 40546 \\ ${ }^{2}$ Department of Dairy Science, Virginia Polytechnic Institute and State University, Blacksburg 24060 \\ ${ }^{3}$ Department of Dairy Science, University of Wisconsin, Madison 53706 \\ ${ }^{4}$ Department of Animal Science, University of Nebraska, Lincoln 68583
}

\section{ABSTRACT}

Development of predictive models of fatty acid (FA) use by dairy cattle still faces challenges due to high variation in FA composition among feedstuffs and fat supplements. Two meta-analytical studies were carried out to develop empirical models for estimating (1) the total FA concentration of feedstuffs, and (2) the apparent total-tract digestibility of total FA $\left(\mathrm{DCFA}_{\mathrm{TTa}}\right)$ in dairy cows fed different fat types. In study 1 , individual feedstuff data for total crude fat (EE) and FA were taken from commercial laboratories (total of 203 feeds, 1,170,937 samples analyzed for total FA, 1,510,750 samples analyzed for total EE), and data for FA composition were collected from the Cornell Net Carbohydrate and Protein System feed library. All feedstuffs were grouped into 7 classes based on their nutritional components. To predict total FA concentration (\% of dry matter) for groups of feeds, the total EE (\% of dry matter) was used as an independent variable in the model, and all models were linear. For forages, data were weighted using the inverse of the standard error (SE). Regression coefficients for predicting total FA from $\mathrm{EE}$ (\% of dry matter) were 0.73 (SE, 0.04), 0.98 (0.02), 0.80 (0.02), $0.61(0.04), 0.92(0.03)$, and 0.93 (0.03), for animal protein, plant protein, energy sources, grain crop forage, by-product feeds, and oilseeds, respectively. The intercepts for plant protein and byproduct groups were different from zero and included in the models. As expected, forages had the lowest total FA concentration (slope $=0.57, \mathrm{SE}=0.02$ ). In study 2, data from 30 studies (130 treatment means) that reported $\mathrm{DCFA}_{\mathrm{TT}}$ in dairy cows were used. Data for animal description, diet composition, intakes of total FA, and DCFA $A_{\text {TTa }}$, were collected. Dietary sources of fat were grouped into 11 categories based on their fat

\footnotetext{
Received August 5, 2019.

Accepted March 27, 2020.

*Corresponding author: mhanigan@vt.edu
}

characteristic and FA profile. A mixed model including the random effect of study was used to regress digested FA on FA intake with studies weighted according to the inverse of their variance (SE). Dietary intake of extensively saturated triglycerides resulted in markedly lower total FA digestion $\left(\mathrm{DCFA}_{\mathrm{TTa}}=44 \%\right)$ compared with animals consuming unsaturated FA, such as Casalts of palm $\left(\mathrm{DCFA}_{\mathrm{TTa}}=76 \%\right)$ and oilseeds $\left(\mathrm{DCFA}_{\mathrm{TTa}}\right.$ $=73 \%)$. Cows fed saturated fats had lower total FA digestion among groups, but it was dependent on the FA profile of each fat source. The derived models provide additional insight into FA digestion in ruminants. Predictions of total FA supply and its digestion can be used to adjust fat supplementation programs for dairy cows.

Key words: fatty acid digestion, feed fatty acid, metaanalysis, dairy cattle

\section{INTRODUCTION}

The use of fat supplements for dairy cows is an important nutritional strategy for increasing the energy density of the diet (Chouinard et al., 2001; Lock et al., 2013) to achieve the desired milk production or adequate body condition (Palmquist and Jenkins, 2017). More recently, sources of dietary lipids have been evaluated relative to manipulation of the bovine milk fatty acid profile with the goal of improving its nutritional value for humans (Rafiee-Yarandi et al., 2016). Moreover, dietary supplementation with essential fatty acids (FA) such as n-3 FA may enhance immune function and reproduction (Moallem, 2018).

Crude fat (ether extract, EE) and total FA concentrations and composition can vary widely among feedstuffs. The EE from animal fats, cereals, and oilseeds is mainly composed of triglycerides (TG) that is approximately 90\% FA (Palmquist and Jenkins, 2003). Forages may have up to $50 \%$ of total EE composed of non-FA components, such as cuticular waxes, pigments, and others (Palmquist and Jenkins, 1980), and 
its concentration can be altered by many factors such as the vegetation stage at harvest (Glasser et al., 2013). For dairy nutritionists, the last edition of the Dairy National Research Council (NRC, 2001) reported only data for EE concentration in feedstuffs. Dietary FA have been predicted from $\mathrm{EE}$ as total $\mathrm{FA}(\%$ of $\mathrm{DM})=$ $\mathrm{EE}(\%$ of $\mathrm{DM})-1$. However, this fails to capture the variation in the proportion of EE represented in total FA, especially for forages.

The composition of dietary FA is associated with the extent of ruminal metabolism and intestinal digestibility. The latter may also be affected by other factors including DMI, the amount of fat ingested, and the property of the fat of the basal diet or supplements (NRC, 2001). The level of ruminal biohydrogenation can be affected by many factors such as dietary level of concentrate (Loor et al., 2004) and starch (Zened et al., 2011), and ruminal pH (Fuentes et al., 2009), but the overall effect is an increase in SFA and a reduction in UFA (Jenkins, 1994). Since 1929, several types of animal or vegetable fats were evaluated, and these studies showed that different levels of lactational performance or milk fat concentration responses to dietary fat were related to the properties and composition of the dietary fat. Moreover, many studies showed that the degree of unsaturation of the individual FA, as well as its chain length, affected total-tract FA digestibility in dairy cows (Palmquist and Jenkins, 2017).

The total FA digestion of many commercial fat supplements containing mixtures of fat sources or high concentrations of a specific FA has varied. It has been observed that total-tract digestion coefficients for FA vary according to the dietary fat sources (Jenkins and Jenny, 1989; Palmquist, 1991; Drackley and Elliott, 1993; Drackley et al., 1994; Elliott et al., 1996; Chan et al., 1997; Espindola et al., 1997; Kalscheur et al., 1997; Oldick and Firkins, 2000). More recently, total FA digestion of fat supplements with high concentrations of specific FA (Boerman et al., 2017; de Souza and Lock, 2018a,b; de Souza et al., 2019a) or produced with different prill sizes (de Souza et al., 2017) has been reported. Variation in total FA digestion between studies and fat supplements indicates that many factors may be involved in the digestion of FA by ruminants (Boerman et al., 2015). We hypothesized that (1) the use of $\mathrm{EE}(\%$ of DM) -1 is not adequate for all type of feeds, and (2) that more precise estimates of total FA digestion in dairy cows could be derived for a range of ingredient categories allowing better predictions of absorbed FA supply. The objectives of this study were (1) to develop empirical models for estimating the total FA concentration in different classes of feedstuffs and (2) to determine the apparent total-tract digestibility of total FA (DCFA $\left.\mathbf{D T}_{\text {TTa }}\right)$ of dairy cows fed different sources of fat.

\section{MATERIALS AND METHODS}

\section{Study 1: Total FA Concentration in Feedstuffs}

Data Collection. A feed database was developed by Tran et al. (2020) composed of data from 4 US commercial feed laboratories (Dairyland Laboratories, Arcadia, WI; Cumberland Valley Analytical Services, Waynesboro, PA; Rock River Laboratory Inc., Watertown, WI; and Dairy One, Ithaca, NY). The data are available from the National Animal Nutrition Program website (www.animalnutrition.org). Tran et al. (2020) removed outlier records when the nutrient value was greater than 3.5 standard deviations (SD) from the mean. The raw data were reduced to treatment means for the current work representing 203 feed ingredients ( $\mathrm{n}=1,808,633$ feed samples). Although differences may be present among laboratories in the results from a given analysis, no attempt was made, per agreement with the participating laboratories, to identify such differences. Ultimately, one would need to use a ring-test approach to clearly identify such differences, and the test would need to be repeated for enough ingredients to determine if it is a generally applicable difference. To our knowledge, such data are not publicly available. The number of observations and mean nutrient concentrations for each ingredient were used for the modeling work. To develop models by feed class, the feedstuffs were grouped into 7 different categories based on historical grouping in the NRC model and on differences in the FA composition of the total fat. The categories were (1) animal protein, (2) plant protein, (3) energy sources, (4) grain crop forages, (5) by-product feeds, (6) forages, and (7) oilseeds (Table 1).

Calculations. Individual FA composition data (\% of total FA) from the Cornell Net Carbohydrate and Protein System (CNCPS) feed library (Higgs et al., 2015; Van Amburgh et al., 2015) were used to estimate the mean individual FA composition ( $\%$ of total FA) and SD for each class of feedstuff.

Regressions. Linear regression models were fitted for each feedstuff class using the $\mathrm{lm}$ function in $\mathrm{R}$ version 3.5.1 (R Core Team, 2018). The following model was adopted:

$$
Y_{i}=a+\beta_{1} x_{i}+e_{i} \sim N\left(\mathbf{0}, \sigma_{e}^{2}\right),
$$

where $Y_{i}$ is the dependent variable (total FA concentration, $\%$ of DM), $a$ is the intercept, $x_{i}$ is the independent 


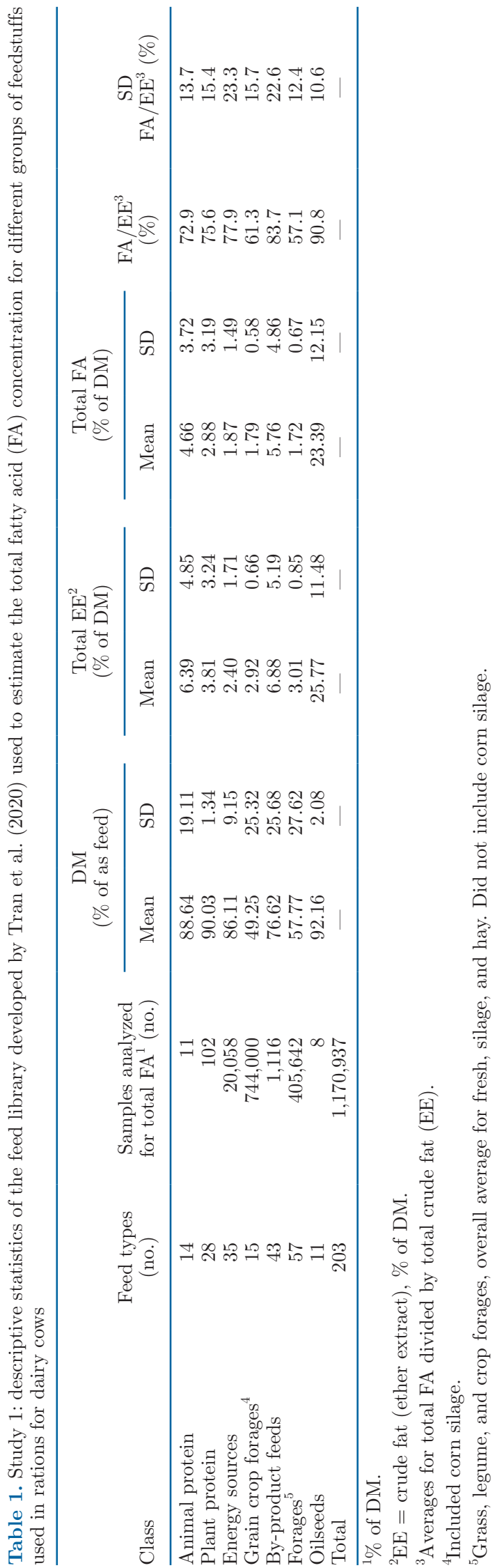

variable (EE, \% of $\mathrm{DM}), \beta_{1}$ represents the slope, and $e_{i}$ is the random error.

Data for forages were weighted using the inverse of the standard error (SE) due to the variability among samples. The root mean square error (RMSE) and concordance correlation coefficient were calculated for each class of feedstuff (Lin, 1989). Plots were created using the ggplot2 package of $\mathrm{R}$ version 3.5.1 (R, 2018) and the Sigma Plot program (version 14.0; Systat Software Inc., San Jose, CA).

\section{Study 2: Total FA Digestion in Dairy Cows}

Metadata. Publications indexed in PubMed, Web of Knowledge, Scopus, and Google Scholar and reporting data for total-tract digestion of total FA in dairy cows (dry and lactating) were collected from the literature. The literature search was conducted between January 2017 and June 2017 using the following key words: dairy, dairy cows, fatty acid, digestibility, and digestion. Publications were initially selected based on titles and abstract information. Articles that reported only duodenal or ileal digestion of total FA were excluded. The selected publications were screened using the eligibility criteria: (1) the work was conducted in dairy cows; (2) the diet description included identification of all ingredients used and the intake of each ingredient could be determined; (3) intakes of DM or total FA were reported; and (4) the $\mathrm{DCFA}_{\mathrm{TT}}$ was reported or could be calculated from other data reported. The final data set included data from 30 publications consisting of 135 treatment means (see Supplemental Table S1 and File S1 for a list; https://doi.org/10.3168/jds.2019 -17407). Data entered, when provided, included animal characteristics, dietary ingredient composition, dietary nutrient composition, feed nutrient composition, DMI, and fecal FA excretion or the $\mathrm{DCFA}_{\mathrm{TTa}}$. The resulting database is available for download at the National Animal Nutrition Program website (Dairy Fat Digestion 2019, https://animalnutrition.org/animal-performance -nutrition).

Calculations. All studies reported either the total FA intake or total FA concentration of the diet (\% of $\mathrm{DM})$, and the majority reported both. When articles did not report the total FA intake $(\mathrm{kg} / \mathrm{d} ; \mathrm{n}=8$ studies), the total FA intake for each treatment was calculated using the total FA concentration of the diet (\% of DM) and DMI $(\mathrm{kg} / \mathrm{d})$ reported for that treatment.

Dietary sources of fat were grouped into 11 categories according to their FA composition and physical and chemical properties. These groups were defined as (1) low-FA feeds, (2) oilseeds, (3) oil (PUFA $>20 \%$, UFA $>65 \%$ ), (4) blended triglyceride (PUFA $<20 \%$, UFA $>56 \%$ ), (5) tallow (MUFA $>36 \%$, UFA $<56 \%$ ), (6) 
SFA-enriched tallow triglycerides (MUFA $>25 \%$, UFA $<36 \%$ ), (7) extensively saturated triglycerides (MUFA $<20 \%$, UFA $<25 \%$ ), (8) Ca-salts of palm FA (MUFA $>30 \%$ ), (9) SFA-enriched tallow FA (MUFA $<15 \%$, UFA <20\%), (10) palmitic acid (about $85 \%$ of C16:0, $>7 \%$ MUFA and $<10 \%$ UFA), and (11) palmitic or stearic acid $(>90 \%, \mathrm{UFA}<2 \%)$.

\section{Statistical Procedures}

All statistical analyses were carried out using the $\mathrm{R}$ program (version 3.5.0; R Core Team, 2018). Descriptive statistics and preliminary plots were performed using the packages psych and ggplot2, respectively. The biological coherence of the database was evaluated, resulting in a total of 130 treatment means being used.

The method used to calculate digestibility for different fat supplements (10 categories) and for the basal diet (low-FA feeds) was to regress apparently digestible FA intakes $(\mathrm{g} / \mathrm{d})$ on total FA intakes $(\mathrm{g} / \mathrm{d})$. Therefore, we used the Lucas test principle to estimate the true digestibility and digestibility of FA for different fat supplements. The intercept was not different from 0 and it was removed from the model. Therefore, the slope represents the estimated true total FA digestibility of each fat supplement and basal diet. The mixed regression model was fitted to achieve maximum log-likelihood using the lme4 package. The model was

$$
\begin{aligned}
& Y=\left(\beta_{1} \times F A I_{\text {low-FA feeds }}\right)+\left(\beta_{2} \times F A I_{\text {oilseeds }}\right) \\
&+\left(\beta_{3} \times\right.\left.F A I_{\text {oil }}\right)+\left(\beta_{4} \times F A I_{\text {blended triglyceride }}\right) \\
&+\left(\beta_{5} \times F A I_{\text {tallow triglyceride }}\right) \\
&+\left(\beta_{6} \times F A I_{\text {SFA enriched tallow TG }}\right) \\
&+\left(\beta_{7} \times F A I_{\text {extensively saturated TG }}\right) \\
&+\left(\beta_{8} \times F A I_{\text {Ca-salts of palm FA }}\right) \\
&+\left(\beta_{9} \times F A I_{\text {SFA enriched tallow FA }}\right) \\
&+\left(\beta_{10} \times F A I_{\text {palmitic acid, } \sim 85 \%}\right) \\
&+\left(\beta_{11} \times\right.\left.F A I_{\text {palmitic or stearic acid, }>90 \%}\right)+S_{i}+\varepsilon
\end{aligned}
$$

where $Y$ is the dependent variable [digestible FA from fat supplements $(\mathrm{n}=10)$ or basal diet (low-FA feeds), $\mathrm{g} / \mathrm{d}], \beta_{1}$ to $\beta_{11}$ represent the true digestibility of each FA class, FAI represent the fixed-effects predictor variables (FA intake from fat supplements $(\mathrm{n}=10)$ or basal diet (low-FA feeds), g/d), and $S_{i}$ and $\varepsilon$ represent the random terms of study and residual error, respectively.

Study was included as a random effect (St-Pierre, 2001). The SE values from studies that used mixed and fixed-effects models were normalized (Roman-Garcia et al., 2016). To prevent overweight among studies, if a SE for a given study was less than half of the mean SE, the value was set to half of the mean SE (Firkins et al., 2001). The inverse of the resulting normalized SE were used to weight each observation. Significance was assumed at $P \leq 0.05$ and a tendency at $0.05<P<$ 0.10 . The model was evaluated for correlations among parameters and variance inflation factors (VIF) were determined. In general VIF values greater than 2.5 may indicate collinearity problems and values greater than 10 are clear indications of collinearity problems. A cutoff of 5 is commonly used. All terms in the model had VIF less than 2, indicating that potential collinearity problems were minimal. The variance-covariance matrix and correlations among independent variables are presented in Supplemental Table S2 (https://doi.org/ 10.3168/jds.2019-17407). Summary statistics of the data set and intakes of total FA for all classes of dietary fat (explanatory variables) are presented in Table 3.

\section{RESULTS AND DISCUSSION}

\section{Total FA Concentration (\% of DM) in Classes of Feeds}

The last version of the Dairy NRC feed library (NRC, 2001) included total EE concentrations of each feed, but not total FA due to limited FA data. As EE is not solely FA (Palmquist and Jenkins, 2003), and total FA concentrations in EE vary among groups of feeds (Table 1), a single conversion factor is not appropriate. Although a conversion factor for each feed would clearly address the problem, it would also negate the need of a conversion as the total FA content of each feed would be known. A compromise that can be supported by the available data is to group feeds and derive a conversion prediction for each group. Following this logic, the various feedstuffs were categorized into 7 classes (Figure 1, 2,3 , and 4) to develop models for predicting the total FA (\% of DM) from EE (\% of DM). We used a large number of forage samples (Figure 5) analyzed for EE and total FA by US laboratories.

A large feed database containing samples analyzed for total EE $(\mathrm{n}=1,510,750)$ and total FA $(\mathrm{n}=1,170,937)$ was used in the present study. Feed composition records provided by 4 major US commercial laboratories (containing samples analyzed between 2011 and 2015) were available for this work via the National Animal Nutrition Program website. Equations for estimating FA (\% of DM) from EE (\% of DM) were developed for 7 groups of feed ingredients, as follows: forages, grain crop forages, energy sources, plant protein, animal protein, oilseeds, and by-product feeds. Descriptive statistics of the feed database are presented in Table 1. 
Total variability in feed nutrient composition is a function of many factors including sampling, analytical variance, species, genetics, growing conditions, maturity, and manufacturing practices. To more adequately understand this variation, total variance should be decomposed into analytical variance, variation caused by differences among laboratories, analytical methods, and variation caused by plant genetics, environment, soil, manufacturing differences, and so on (St-Pierre and Weiss, 2015). In particular, use of different chemical treatments and solvents (i.e., extraction with diethyl ether, petrol ether, ether, acid hydrolysis, and base hydrolysis) may lead to different ingredient $\mathrm{EE}$ values, which could introduce bias to the model. Glasser et al. (2013) reported differences in FA content in forages when different methods for ether extraction were used for fresh forage and hay, but not for silages.

Given that there is not a standard method for total EE analysis, animal feed laboratories may adopt dif- ferent techniques to extract lipids from animal feeds based on their resources and costs. The use of different methods for estimating $\mathrm{EE}$ concentration may reduce the reproducibility of results among laboratories. Therefore, total EE concentration of a given feed can also depend on the method used for lipid extraction. In animal nutrition, the most common chemical methods used for fat analysis include lipid extraction with diethyl ether (AOAC International, 2012; methods 920.39 and 2003.05), petroleum ether (AOAC International, 2012; method 945.16), acid hydrolysis (AOAC International, 2012; method 954.02), and the modified Mojonnier method (AOAC International, 2012; method 932.06). Moreover, near infrared spectroscopy is commonly used to estimate EE concentration of feeds because of cost- and time-saving factors. In our work, the reference methods used to estimate total EE in feeds were extraction with ethyl or petroleum ether (Tran et al., 2020). Although those methods are still widely used
Plant Protein

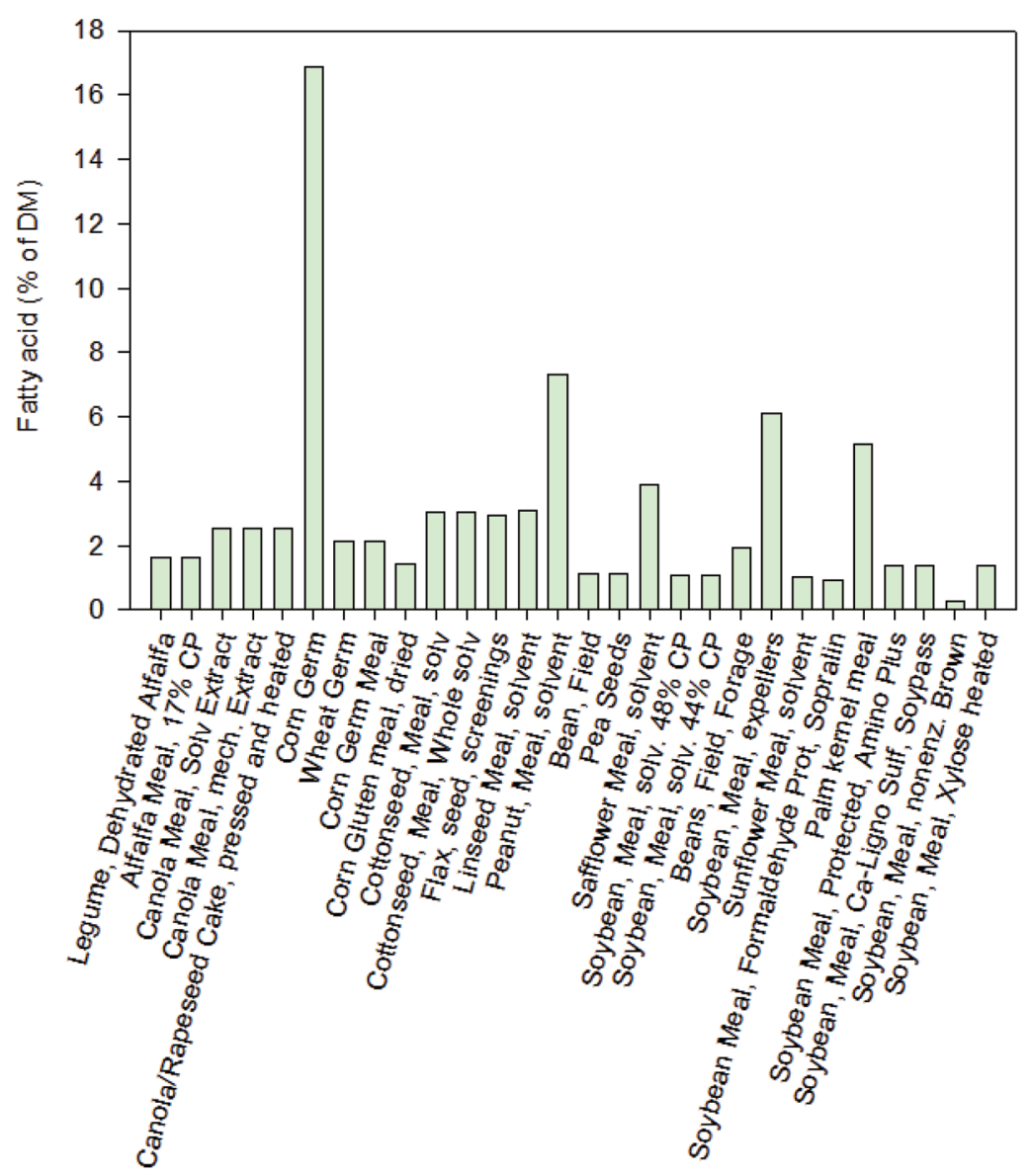

Animal Protein

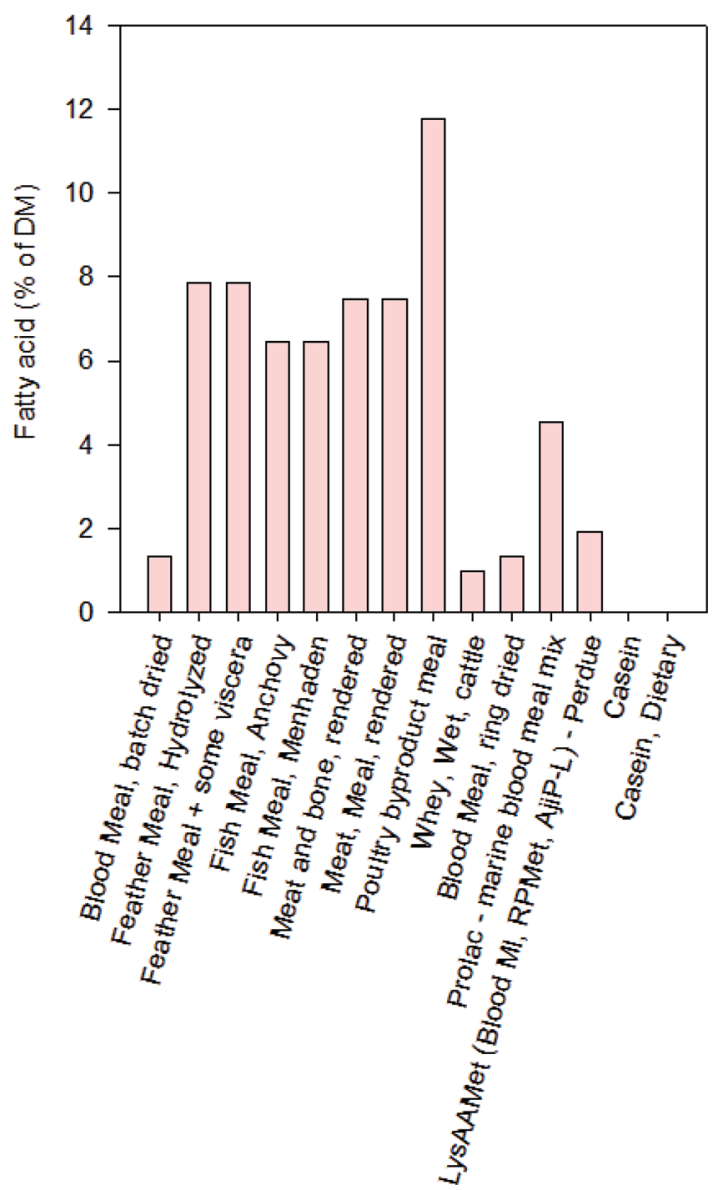

Figure 1. Total fatty acid concentrations for ingredients classified as plant and animal proteins. solv = solvent; mech = mechanical; Prot = protected; Sopralin (Trouw Nutrition, Northwich, Cheshire, UK); AminoPlus (Ag Processing Inc., Omaha, NE); Ca-Ligno Sulf = calcium lignosulfonate; nonenz. brown $=$ nonenzymatic browning. 


\section{Grain crop forages}

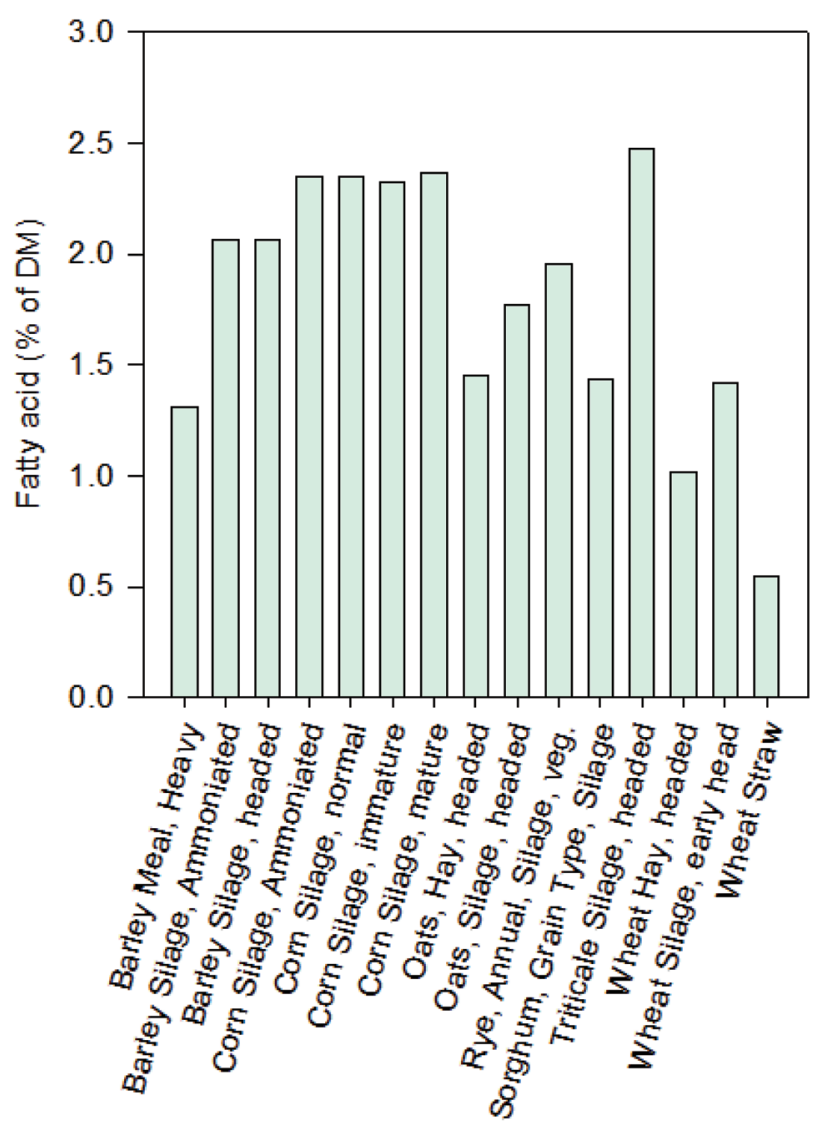

Oilseeds

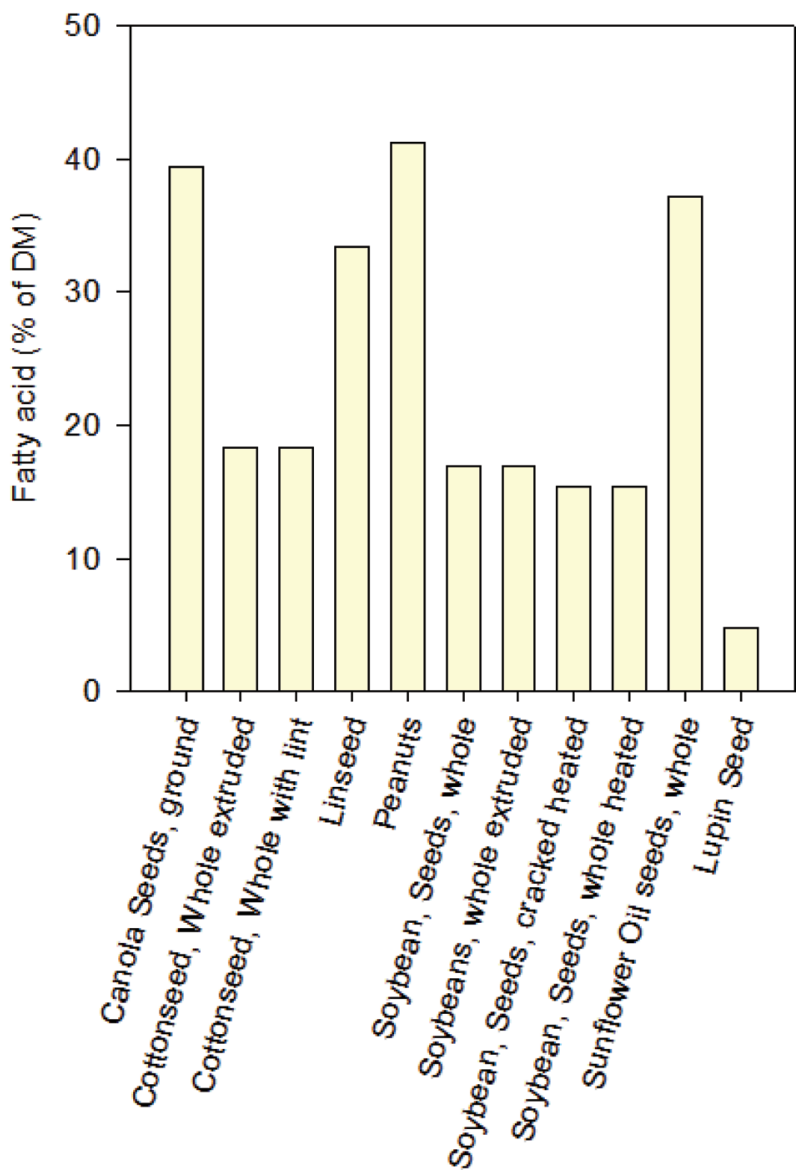

Figure 2. Total fatty acid concentrations for ingredients classified as grain crop forages and oilseeds. veg. $=$ vegetative.

by animal feed analysis laboratories, these techniques have limitations that should be considered. Diethyl ether extraction (AOAC International, 2012; method 920.39) may overestimate total EE concentration due to the extraction of water-soluble components (urea and hexoses). On the other hand, when this method is performed with hexanes, the EE concentration of a feed could be underestimated because of a lower lipid extraction. Acid hydrolysis is often used to analyze total EE in commercial fat supplements, pet foods, or heat-processed feeds that contain covalent and ionic bonding among lipids, protein, and carbohydrates. This method increases the lipid extraction in feed samples, resulting in a higher total FA concentration. However, the use of this method for corn silage may increase the extraction of nonfat components such as nonvolatile lactic acid (Palmquist and Jenkins, 2003). To improve predictions of nutrient supply for dairy cows, further research is required to determine the effect of laboratory methods on chemical composition of feeds, and if necessary, to include the laboratory method in feed composition models.

The animal protein feed group was represented mostly by blood meal, feather meal (hydrolyzed or with some viscera), and meat meal (Supplemental Figure S1; https://doi.org/10.3168/jds.2019-17407). Both hydrolyzed feather meal and blood meal have been used in diets for dairy cows as sources of EAA given relatively greater RUP (Palmquist et al., 1993; Santos et al., 1998). The averages for EE and total FA for animal protein feeds were 6.39 and $4.66 \%$ of DM, respectively (Table 1). The EE value was slightly greater than the value of $6.06 \%$ reported by the NRC (2001) for the animal protein feed group. The plant protein group contained predominantly different types of canola and soybean meal, which are considered important sources of protein in diets for dairy cows (Supplemental Figure S2; https://doi.org/10.3168/jds.2019-17407). The average values for $\mathrm{EE}$ and total $\mathrm{FA}$ were 3.81 and $2.88 \%$ of DM, respectively. For this category, NRC (2001) re- 


\section{Energy sources}

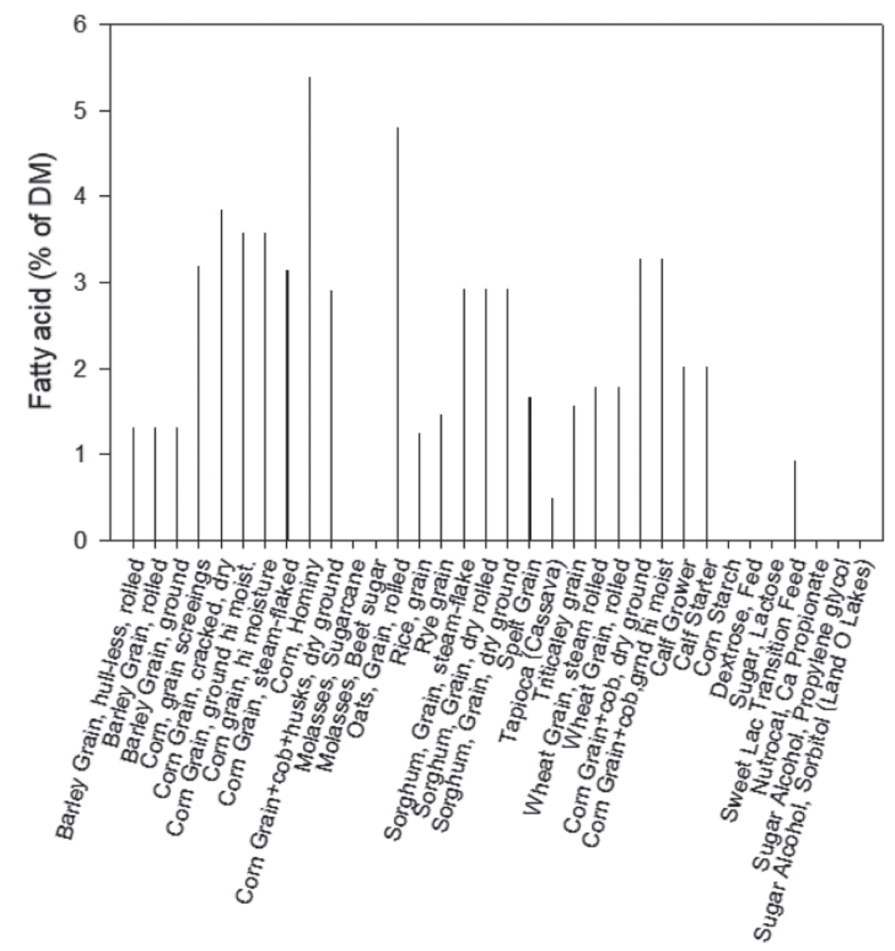

\section{By-product feeds}

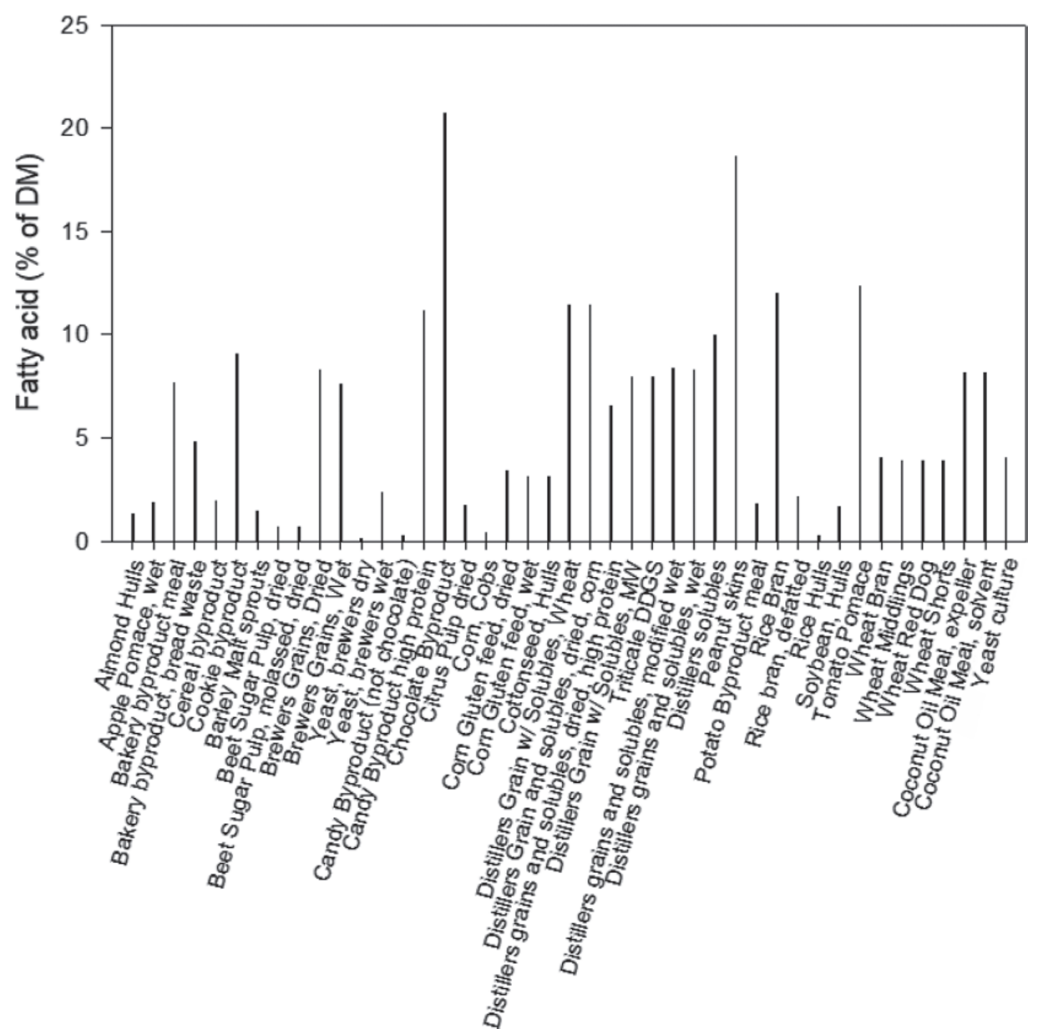

Figure 3. Total fatty acid concentrations for ingredients classified as energy sources and by-product feeds. MW = modified wet; DDGS = dry distillers grains with solubles; grnd = ground; Sweet Lac Transition (Westway Feed Products LLCm, Tomball, TX); NutroCal (Kemin Industries, Inc., Des Moines, IA); Sorbitol (Land O'Lakes, Arden Hills, MN). 


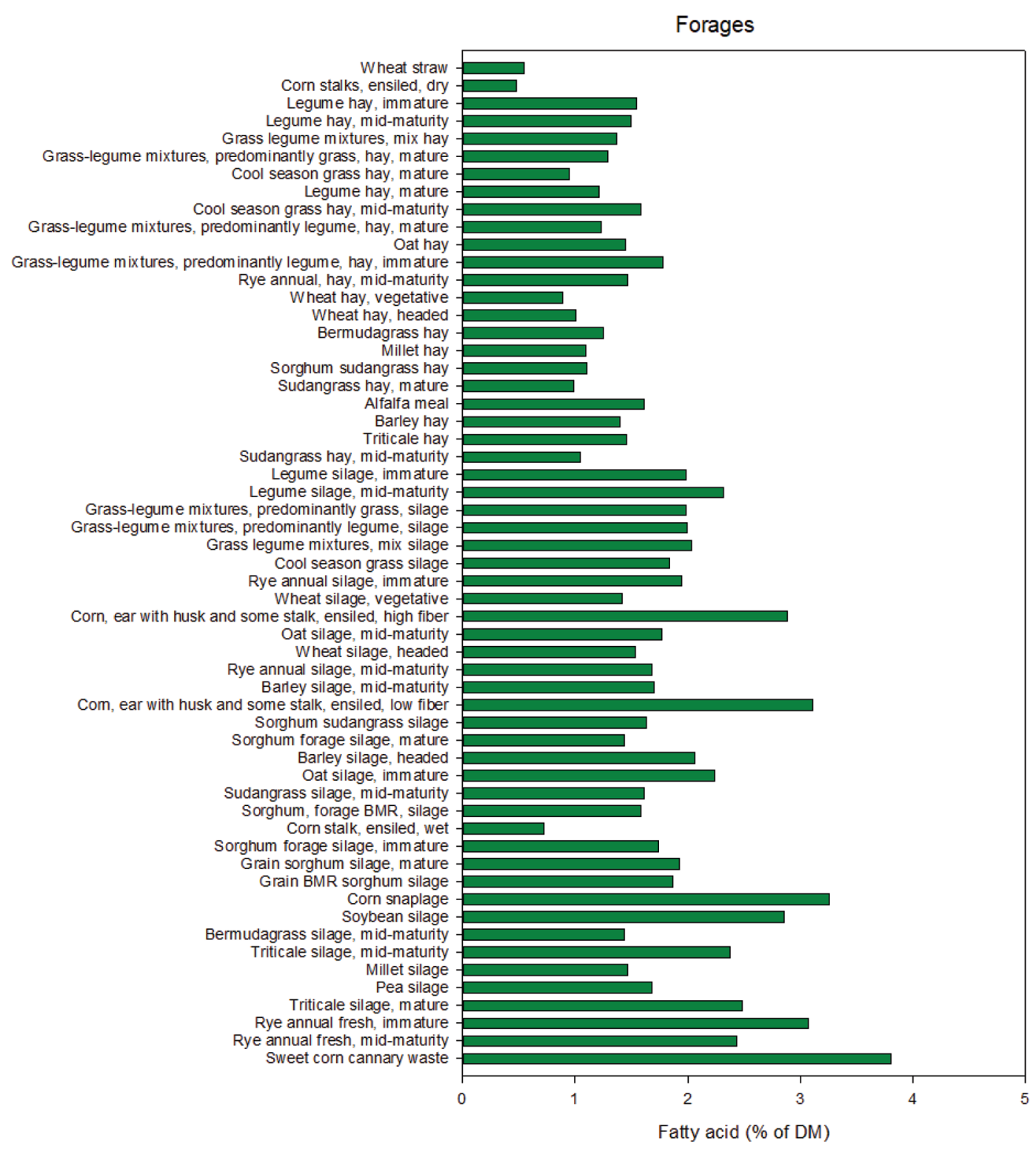

Figure 4. Total fatty acid concentrations for ingredients classified as forages. BMR = brown midrib.

ported an EE value of $10.25 \%$ of DM. This large difference may be due to the fact that NRC (2001) included some oilseeds (i.e., sunflower oil seeds, $41.9 \% \mathrm{EE}$ ) into the group, which consequently generated a greater EE average.

Ingredients categorized as energy sources and grain crop forages (Supplemental Figures S3 and S4; https:/ / doi.org/10.3168/jds.2019-17407) often have low concentrations of EE and total FA. The NRC (2001) reported values for EE varying from 0.2 to $5.1 \%$ of $\mathrm{DM}$ for this category. The current work found average EE ranging from 0.6 to $7.2 \%$ of DM. The grain crop forages had EE values of $2.92 \%$ of DM that were very close to the value of $2.86 \%$ reported by NRC (2001). Grain crop forages, forages, and energy sources (Table 1) had the lowest $\mathrm{SD}$ values for both EE and total FA concentrations (\% of DM). This could be related to the small total FA concentration for this feed class, which resulted in a low variation among samples.

By-product feeds (Supplemental Figure S5; https:/ /doi.org/10.3168/jds.2019-17407) are mostly residues from human food and fuel production. There are several types of by-product feeds, and their composition can vary greatly depending on the processing technique adopted by the food or ethanol industries. This feed class had the second highest SD for EE and total FA concentrations in comparison with other classes of feeds. Oilseeds (Supplemental Figure S6; https://doi 

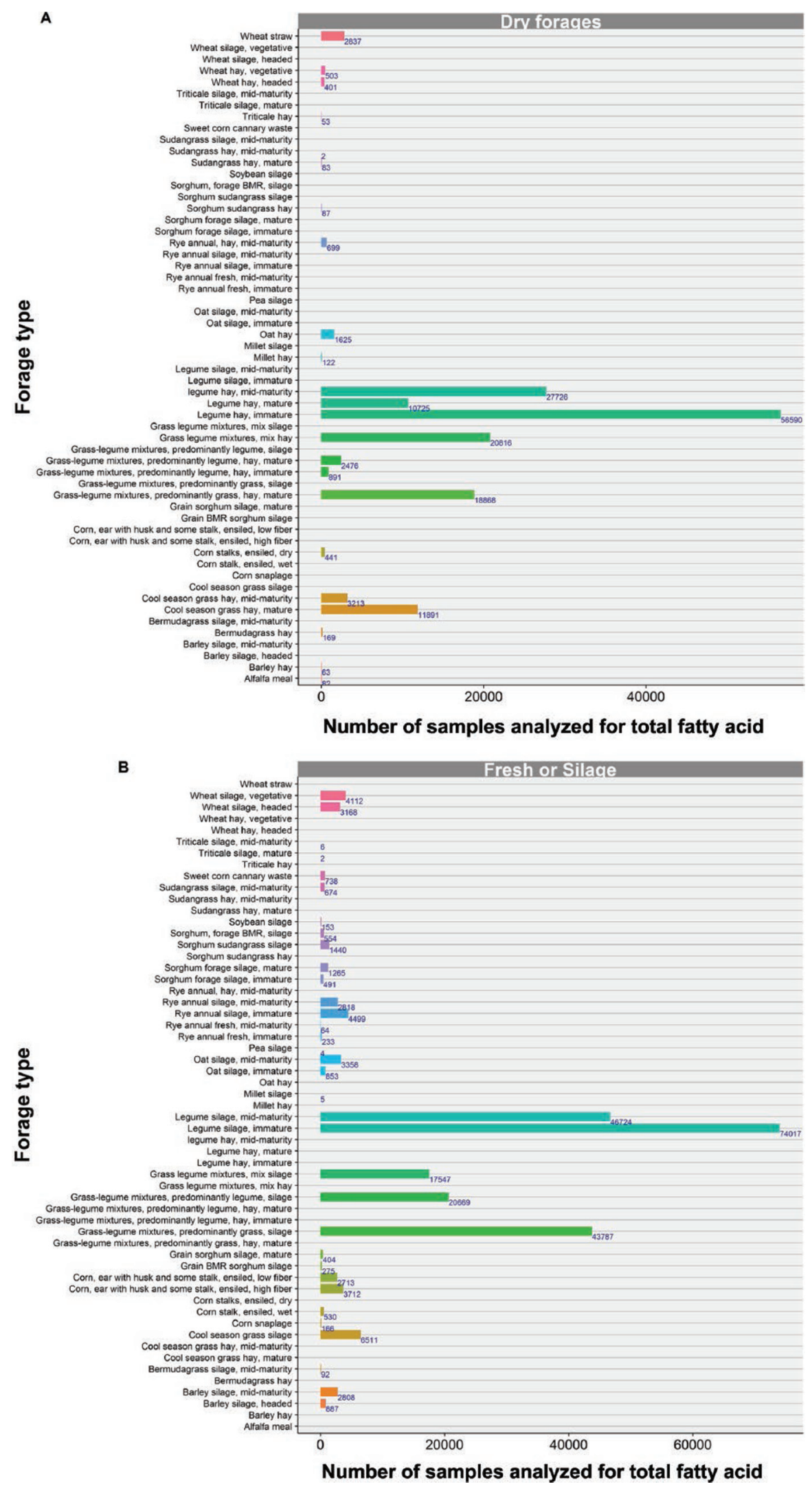

Figure 5. The number of samples from each forage used to develop the model to predict concentrations of total fatty acids in forages. BMR $=$ brown midrib. 


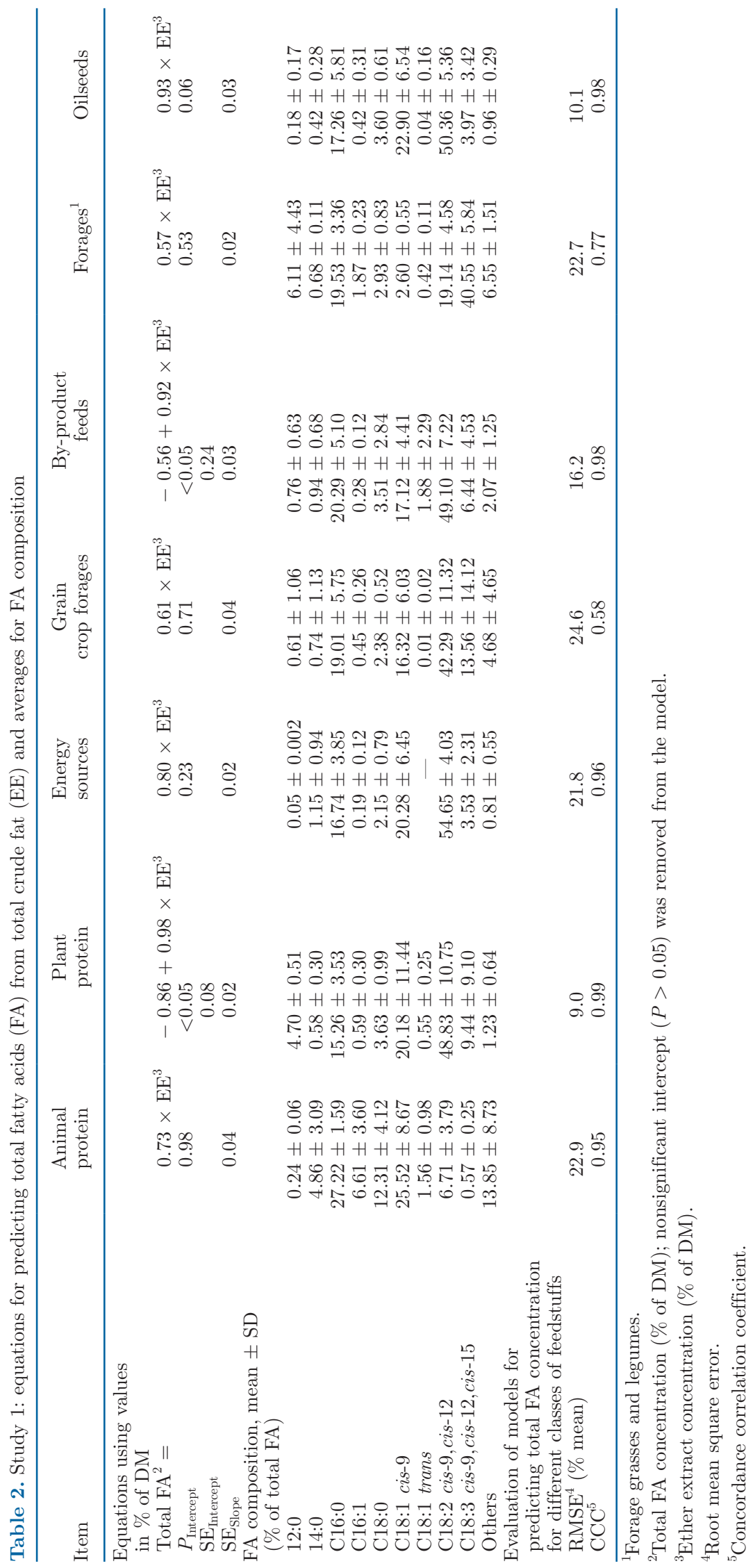


.org/10.3168/jds.2019-17407) are an important source of UFA in diets for dairy cows (Glasser et al., 2008a), but differences in total FA concentration between oilseeds, and among this and other groups of feedstuffs, were large (Table 1), suggesting that oilseeds must be kept in a separate group for predicting total FA from EE of feeds.

The regression results indicated that the contribution of FA to EE differed among feed classes (Table 2). Oilseeds, by-product feeds, and plant protein had slope coefficients of $0.93,0.92$, and 0.98 , respectively, with high concordance correlation coefficient values $(>0.97)$, indicating that greater than $85 \%$ of the observed EE was derived from total FA. The intercept values for plant protein and by-product groups were different from zero, and therefore, they were included in the models. However, forages and grain crop forages had slope coefficients of 0.57 and 0.61 , respectively, indicating that just over half of the EE were derived from total FA.

The best model for predicting total FA concentration in forages had a single predictor of EE concentration (\% of DM; Table 2). This linear model was fitted without an intercept $(P>0.05)$ and using data from 57 different types of forage that are commonly used in diets for dairy cows (Figures 4). The Akaike's information criterion corrected for sample size (AICc) value was 65 with an RMSE of $0.39 \%$ of DM. When CP concentration was used as a sole predictor of total FA concentration in forages, the slope was significant $(P<0.05)$, but the AICc and RMSE values increased considerably $(\mathrm{AICc}=116$; RMSE $=0.64)$. When both $\mathrm{EE}$ and $\mathrm{CP}$ were used as predictors, there were no problems with multicollinearity (VIF $=2.62)$, but the AICc increased to 69. Therefore, the best model based on AICc used only EE concentrations (\% of DM) as a predictor of total FA concentrations (\% of DM) in forages.

Ether extract and total FA concentration in forages were highly correlated $(\mathrm{r}=0.81)$, and the correlation between $\mathrm{EE}$ and $\mathrm{CP}$ was positive $(\mathrm{r}=0.46)$. Averages for EE and total FA concentration for fresh forage and silages were higher compared with hay, but there were no significant differences $(P>0.05)$ in FA concentrations among types of forages (fresh, dry, or silages).

Individual models were developed to predict total FA concentration for each type of forage (fresh, silages, and hay), but the slope coefficients were similar (fresh $=0.59$, silages $=0.57$, hay $=0.54)$, and the model developed for all forages predicted with lower RMSE values than the independent models (model for all forage RMSE $=23 \%$ of mean; model for each type of forage RMSE $=33 \%$ of mean). Therefore, splitting the database by forage type resulted in less robust models, which reduced their precision.
Glasser et al. (2013) used data from the literature to develop a model that considered both EE concentration and method of conservation (fresh, silage, hay). Although the authors did not report correlations among independent variables, hay has a lower mean EE concentration than other forages, which may lead to collinearity and redundancy of predictors if both EE and type of forage are used in the model. The negative association between $\mathrm{EE}$ and total FA in silages described in that study was not observed in the present work, which may be due to the much larger sample size used in the current work. The effect of botanical families (grasses vs. legumes) was not evaluated in the current work, but Glasser et al. (2013) did not find any differences by botanical family for total FA in forages.

The EE slope coefficient of $0.57 \mathrm{~g}$ of FA/g of EE is in agreement with previous data reported by Palmquist and Jenkins (1980), where as much as $50 \%$ of forage $\mathrm{EE}$ was composed of non-FA components. Even though a study using a small sample of 13 plant materials at 3 harvest times reported that concentration of total FA and the FA profile varied among species and by management (Clapham et al., 2005), our results indicated that the FA concentration of EE did not differ across forage types that were defined by 405,642 forage samples. Therefore, individual equations for each forage species appear to be unnecessary to estimate total FA concentration from EE of feeds (Table 2) when data from feed analysis are not available.

Glycolipids and phospholipids are the major lipids in forages and are present mostly in the leaf chloroplasts. Leaf lipids also contain a high proportion of PUFA (Harfoot, 1981), which may vary according to different factors. Models for predicting FA composition of forages should be time dependent as the nutritional composition of the plant changes with increasing plant age. Many factors can affect FA composition in forages such as species (Dewhurst et al., 2001), vegetation stage at harvest and conservation methods (Glasser et al., 2013), N fertilization (Boufaïed et al., 2003), as well as the wilting and shading process (Dewhurst and King, 1998).

Agronomic practices such as $\mathrm{N}$ fertilization also could increase the total FA and C18:3 concentrations in forages by about $26 \%$ and $40 \%$, respectively (Boufaied et al., 2003). The growth stage is also an important factor that affects the individual FA composition of forage. A study evaluating timothy reported that the total FA and concentrations of $\mathrm{C} 16: 0, \mathrm{C} 16: 1, \mathrm{C} 18: 2$, and $\mathrm{C} 18: 3$ decreased with the increasing plant age, but concentrations of $\mathrm{C} 12: 0, \mathrm{C} 14: 0, \mathrm{C} 18: 0$, and $\mathrm{C} 18: 1$ did not change. The changes in FA composition could be associated with a decrease in the proportion of leaves with the 
Table 3. Study 2: descriptive statistics for data used to predict total fatty acid (FA) digestibility for 11 classes of dietary FA used in rations for dairy cows

\begin{tabular}{|c|c|c|c|c|c|c|}
\hline Variable & $\mathrm{n}$ & Mean & $\mathrm{SD}$ & Minimum & Maximum & SE \\
\hline \multicolumn{7}{|l|}{ Animal characteristic } \\
\hline BW $(\mathrm{kg})$ & 135 & 597 & 77 & 430 & 744 & 7 \\
\hline Milk fat $(\%)$ & 111 & 3.43 & 0.49 & 2.11 & 4.67 & 0.05 \\
\hline Milk protein (\%) & 111 & 3.12 & 0.20 & 2.76 & 3.74 & 0.02 \\
\hline Milk lactose (\%) & 33 & 4.78 & 0.15 & 4.48 & 5.01 & 0.03 \\
\hline $\mathrm{CP}$ & 135 & 17.44 & 1.50 & 13.11 & 23.06 & 0.13 \\
\hline Crude fat & 135 & 5.86 & 1.70 & 2.66 & 9.49 & 0.15 \\
\hline FA & 135 & 5.27 & 1.63 & 1.99 & 9.23 & 0.14 \\
\hline NDF & 135 & 31.94 & 3.72 & 21.41 & 39.04 & 0.32 \\
\hline Starch & 135 & 26.21 & 5.74 & 14.40 & 45.02 & 0.49 \\
\hline Ash & 135 & 7.64 & 1.04 & 5.33 & 9.92 & 0.09 \\
\hline \multicolumn{7}{|l|}{ Intake $(\mathrm{kg} / \mathrm{d})$} \\
\hline Total FA from tallow TG & 19 & 0.514 & 0.216 & 0.126 & 0.880 & 0.050 \\
\hline Total FA from moderately saturated tallow TG & 4 & 0.908 & 0.381 & 0.443 & 1.372 & 0.190 \\
\hline Total FA from saturated TG & 9 & 0.650 & 0.298 & 0.296 & 1.218 & 0.099 \\
\hline Total FA from Ca-salts of palm FA & 13 & 0.596 & 0.304 & 0.065 & 1.099 & 0.084 \\
\hline Total FA from partially saturated tallow & 14 & 0.749 & 0.261 & 0.308 & 1.213 & 0.070 \\
\hline Total FA from palmitic acid, $\sim 85 \%$ & 5 & 0.443 & 0.027 & 0.428 & 0.491 & 0.012 \\
\hline Total FA from palmitic or stearic acid, $>90 \%$ & 5 & 0.425 & 0.147 & 0.208 & 0.617 & 0.066 \\
\hline \multicolumn{7}{|l|}{ Apparent digestibility of FA in the total-tract of dairy cows } \\
\hline Average $(\%)$ & 135 & 70.14 & 8.88 & 40.2 & 93.1 & 0.76 \\
\hline
\end{tabular}

increasing of plant maturity (Boufaied et al., 2003). In addition, the conservation could affect the FA composition of plants. Significant losses in total FA and C18:3 were due to the extended wilting process (Dewhurst and King, 1998). Moreover, it is necessary to consider that grasses and legumes may have different concentrations of individual FA, where grasses (orchardgrass and timothy) had a higher concentration of C18:3, although both legumes and grasses contained a similar total FA concentration (Boufaied et al., 2003).

Our study did not develop models for predicting FA composition of forages or other feed categories, but we described averages for FA composition for all feed classes based on the CNCPS feed library. For academic purposes, summarizing individual FA composition data by mean could be useful to identify the main sources of a given specific FA in different types of feeds. For example, in Table 2 it is possible to identify that forages are the major source of C18:3 (average of $40.5 \%$ of total FA), whereas energy feeds are the major source of C18:2 (average of $54.6 \%$ of total FA). For ration formulation, the use of individual FA composition from laboratories are recommended, mainly when a wilting process is adopted as a method of forage conservation.

\section{Total FA Digestion in Dairy Cows}

Descriptive statistics for the data used in study 2 are shown in Table 3. The average daily intake of total FA was $1.09 \pm 0.39 \mathrm{~kg} / \mathrm{d}$ for cows averaging $31.4 \pm$ $8.3 \mathrm{~kg} / \mathrm{d}$ of milk ( $\mathrm{n}=347$ cows). The concentration of total dietary FA varied from 2.0 to $9.2 \%$ of DM, which indicated significant variation across studies. The average total dietary FA concentrations was $5.27 \%$ of DM, which was similar to the value reported by Boerman et al. (2015) for a smaller data set containing 15 publications and 61 treatments. The average digestibility of total FA was $70.1 \% \pm 8.8$ (SD), which was higher than the value of $67.3 \% \pm 11.3$ reported in a meta-analysis that used 56 treatment means (Weld and Armentano, 2017).

The model for predicting the total FA digestion of different types of dietary lipids initially contained an intercept, but it was found to be insignificant $(P>$ 0.05 ), and thus was excluded. The slope coefficients for digestibility $\left(\mathrm{DCFA}_{\mathrm{TTa}}\right)$ are shown in Table 4 . The low-FA feed group contained low-fat feed ingredients commonly used in the basal diet (no fat supplements) of cows. It can contribute up to $3.2 \%$ of the total di- 
Table 4. Apparent total-tract fatty acid digestibility coefficients $\left(\mathrm{DCFA}_{\mathrm{TTa}}, \mathrm{g} / \mathrm{g}\right.$ total fatty acid; FA) for 11 sources of total FA typically used in rations for dairy cows

\begin{tabular}{lcccc}
\hline Class & $\begin{array}{c}\text { No. of treatment means } \\
\text { (No. of articles) }\end{array}$ & $\begin{array}{c}\text { DCFA }_{\text {TTa }} \\
\text { (g/g of FA) }\end{array}$ & SE & Category \\
\hline Low-FA feeds & $130(30)$ & 0.73 & 0.03 & $1^{1}$ \\
Oilseeds $_{\text {Oil }^{2}}$ & $61(15)$ & 0.73 & 0.04 & $1^{1}$ \\
Blended triglyceride $^{3}$ & $16(6)$ & 0.70 & 0.03 & $1^{1}$ \\
Tallow triglyceride $^{5}$ & $12(6)$ & 0.63 & 0.03 & $2^{4}$ \\
SFA-enriched tallow triglycerides $^{7}$ & $19(10)$ & 0.68 & 0.03 & $3^{6}$ \\
Extensively saturated triglycerides $^{8}$ & $4(2)$ & 0.61 & 0.04 & $2^{4}$ \\
Ca-salts of palm fatty acid $^{10}$ & $9(6)$ & 0.44 & 0.03 & $4^{9}$ \\
SFA-enriched tallow fatty acid & $13(7)$ & 0.76 & 0.03 & $1^{1}$ \\
Palmitic acid, about 85\% of C16:0 $^{12}$ & $14(7)$ & 0.69 & 0.02 & $3^{6}$ \\
Palmitic or stearic acid $>90 \% \%^{13}$ & $5(2)$ & 0.73 & 0.08 & $1^{1}$ \\
\hline
\end{tabular}

${ }^{1}$ Category 1: low-FA feeds, oilseeds, palmitic acid, oil, and Ca-salts of palm FA (slope $=0.732, \mathrm{SE}=0.011$ ). No differences between the model fitted with 11 categories and grouped model using category $1(P=0.35)$.

${ }^{2}>20 \%$ PUFA and $>65 \%$ UFA.

${ }^{3}<20 \%$ PUFA and $>56 \%$ UFA

${ }^{4}$ Category 2: blended triglyceride and SFA-enriched tallow triglycerides (slope $=0.618, \mathrm{SE}=0.023$ ). No differences between the model fitted with 11 categories and grouped model using categories 1 and $2(P=0.48)$.

${ }^{5}>36 \%$ MUFA and $<56 \%$ UFA.

${ }^{6}$ Category 3: tallow triglyceride and SFA-enriched tallow triglycerides (slope $=0.677, \mathrm{SE}=0.017$ ). No differences between the model fitted with 11 categories and grouped model using categories 1,2 , and $3(P=0.57)$. ${ }^{7}>25 \%$ MUFA and $<36 \%$ UFA.

${ }^{8}<20 \%$ MUFA and $<25 \%$ UFA.

${ }^{9}$ Category $4:<20 \%$ MUFA and $<25 \%$ UFA.

${ }^{10}>30 \%$ MUFA.

${ }^{11}<15 \%$ MUFA and $<20 \%$ UFA.

${ }^{12}>7 \%$ MUFA and $<10 \%$ UFA.

${ }^{13}<2 \%$ UFA

${ }^{14}$ Category 5: $<2 \%$ UFA.

etary FA on a DM basis (Weld and Armentano, 2017). Basal diets for cows often contain corn silage, grass silage, soybean meal, and corn-based concentrate. Corn silage and soybean meal are sources of linoleic acid (C18:2), whereas grass silages are sources of linolenic acid (C18:3) and PUFA (Khan et al., 2012). The lowFA feed group had a DCFA $_{\mathrm{TTa}}$ of $0.73 \mathrm{~g} / \mathrm{g}$ of FA $(\mathrm{SE}=$ $0.03)$, and this value is in agreement with the digestibility of $73.1 \%$ reported by Harvatine and Allen (2006) for cows fed a basal diet containing corn silage and corn. On the other hand, recent studies reported higher total FA digestibility for basal diets (about 80\%; Boerman et al., 2017; de Souza et al., 2017). This difference may be due to the variation among feed ingredients used in the control diet (no fat supplements).

Oilseeds are the major source of UFA in the basal diets of dairy cows. The slow release of FA from the oilseed matrix confers partial ruminal protection minimizing the biohydrogenation of UFA by ruminal microbes. This group was represented mainly by linseed, sunflower seed, flaxseed, soybeans, canola (rapeseed), and cottonseed. The oilseeds group had a $\mathrm{DCFA}_{\mathrm{TTa}}$ of $0.73 \mathrm{~g} / \mathrm{g}$ FA. Oilseeds contain mainly C18:1, C18:2, and C18:3 FA (Glasser et al., 2008a), which may have contributed to high digestibility.

Palmitic FA (C16:0) is often used in fat supplements for dairy cows, but its concentration can vary widely among fat supplements. Prilled FA are generally composed mainly of SFA, such as C16:0 and stearic (C18:0) acids. They are used in diets to avoid problems arising from partial ruminal hydrogenation of UFA (Palmquist and Jenkins, 2017). Studies reported coefficients of digestion for C16:0 of 75\% (small intestine, 20 studies with 70 treatments; Lock et al., 2006) and 76.5\% (apparent intestinal digestibility, 15 studies with 43 treatments; Boerman et al., 2015), respectively. The current findings of $73 \%$ for the palmitic acid group ( $85 \%$ ) (Table 4) were slightly less than the prior work and almost identical to the value of $72.5 \%$ used in the CNCPS model version 6.5 for postruminal C16:0 digestibility for field use (Van Amburgh et al., 2015). Variation in the digestion of $\mathrm{C} 16: 0$ by dairy cows could be partially explained by differences in fat supplements used among studies, as well as the level of supplementation in the diet. The total FA digestibility may also be influenced by individual FA present in supplements; for example, 
a meta-analysis using individual data from 5 studies showed that the intake of $c i s-9 \mathrm{C} 18: 1$ positively affected total FA digestion, whereas a high intake of C18:0 may reduce the total FA digestibility by reducing the digestibility of C16 and C18 FA (Lock and de Souza, 2017).

Calcium salts of palm FA (Ca-FA) is a supplement composed of FA blended with calcium ions. This results in low FA solubility in the rumen. In our work, cows fed Ca-FA supplements had the highest total FA digestibility $(0.76 \mathrm{~g} / \mathrm{g} \mathrm{FA}, \mathrm{SE}=0.03)$ compared with other sources of dietary fat (Table 4). A recent study reported a higher value for total FA digestibility of cows fed Ca-FA (78.8\%; de Souza and Lock, 2018b). Differences in the digestion of Ca-FA could be related to the basal diet composition. Diets with a high concentration of fermentable carbohydrates may reduce the rumen $\mathrm{pH}$, which may result in dissociation of Ca-FA releasing more UFA in the rumen (Sukhija and Palmquist, 1990). This potentially changes the profile of FA that reach the intestine of the cow, as well as their digestibility.

The blended TG group was composed mainly of animal and vegetable fats. This group had a $\mathrm{DCFA}_{\mathrm{TTa}}$ of $0.63 \mathrm{~g} / \mathrm{g}$ FA $(\mathrm{SE}=0.03)$ with a proportion of PUFA representing less than $20 \%$, whereas the UFA represented more than $56 \%$ of the total FA. Blended TG supplements may have different UFA:SFA ratios. Often vegetable oils and animal products are mixed in different proportions, which can change the FA profile of this supplement, as well as its digestibility. Wu et al. (1991) reported the individual FA composition for an animal-vegetable fat blend of $17.0 \%, 17.2 \%$, and $34.5 \%$ for C16:0, C18:0, and C18:1 cis, respectively. For this supplement, depending on the level of biohydrogenation of the $\mathrm{C} 18: 1$ cis and trans in the rumen, the amount of C18:0 in the duodenal FA flow may increase. A meta-analytical study showed that increased flow of C18:0 may reduce its digestibility (Boerman et al., 2015) in dairy cows possibly due to its low solubility in intestinal micelles (Glasser et al., 2008b). Therefore, the digestion of total FA for the blended TG group may be associated with its FA profile, primarily the concentration of C18:0 FA. Moreover, other mechanisms can be associated with lower digestibilities of TG such as particle size (Eastridge and Firkins, 1991; de Souza et al., 2017), iodine value (Firkins and Eastridge, 1994; Palmquist and Jenkins, 2017), melting point (Bainbridge and Kraft, 2016; Boerman et al., 2017), and the time of action of intestinal lipases and FA absorption (de Souza and Lock, 2018b).

Our model predicted DCFA $\mathrm{TTa}_{\mathrm{Ta}}$ of $0.70 \mathrm{~g} / \mathrm{g}$ FA (SE $=0.03)$ for the oil group. This group was composed mainly of soybeans, canola seed, and fish oils, which are sources of PUFA. The SFA enriched with tallow FA and SFA enriched with tallow TG had DCFA ${ }_{\mathrm{TTa}}$ of
$0.69 \mathrm{~g} / \mathrm{g}$ FA $(\mathrm{SE}=0.02)$ and $0.61 \mathrm{~g} / \mathrm{g}$ FA $(\mathrm{SE}=0.04)$, respectively. Tallow is a source of SFA that contains mainly C16:0, C18:0, and C18:1 cis FA. In ruminants, TG, phospholipids, and glycolipids from the diet are hydrolyzed by ruminal bacteria and protozoa, releasing free FA (Buccioni et al., 2012), where the UFA can potentially be biohydrogenated to more saturated FA (Jenkins, 1994). Because of ruminal lipolysis, little TG reaches the intestine of the cow (NRC, 2001). Evidence suggests that fat supplements consisting of FA may have higher digestibility than fats containing high amounts of TG. A recent study showed that a TG fat supplement $(78.6 \%$ of $\mathrm{C} 16: 0)$ had a lower total FA digestibility compared with a FA supplement $(84.2 \%$ of C16:0; de Souza and Lock, 2019). Therefore, differences in total FA digestion among SFA enriched with tallow FA and SFA enriched with tallow TG could be partially explained by the form that those FA reached the intestine of the cow. Large amounts of TG in the intestine of the cow may not be lipolyzed because the pancreas may not produce enough lipases (NRC, 2001). Moreover, the FA profile of those FA supplements were different (SFA enriched with tallow FA $=$ MUFA $<15 \%$ and UFA $<20 \%$; SFA enriched with tallow TG $=$ MUFA $>25 \%$ and UFA $<36 \%$ of FA), and this may have contributed to the difference in total FA digestion between groups. Overall, SFA has a high melting point, which may result in low total FA digestibility (Loften et al., 2014) due to its low solubility (Bainbridge and Kraft, 2016), which may reduce the contact between FA with digestive enzymes in the small intestine (Drackley, 2004).

As expected, extensively saturated TG had a low $\mathrm{DCFA}_{\text {TTa }}(0.44 \mathrm{~g} / \mathrm{g} \mathrm{FA}, \mathrm{SE}=0.03)$ that could be associated with its insolubility, resulting in a decrease in hydrolysis and absorption in the small intestine (Palmquist and Jenkins, 2017). Fat supplements containing elevated levels of C16:0 or C18:0 (>90\%) also had markedly low total FA digestion $(0.31 \mathrm{~g} / \mathrm{g}$ FA, SE $=0.05)$. Although the latter class presented only 3 publications $(\mathrm{C} 16: 0=1$ study; $\mathrm{C} 18: 0=2$ studies $)$ with 5 treatment means, the data were consistent, resulting in similar SE of the estimates as for the other classes. The products used in those studies are not commercially available and were manufactured exclusively for those trials. On the other hand, Rico et al. (2017) evaluated different levels of a C16:0-enriched supplement (0, 0.75, 1.5 , and $2.25 \%$ ) containing about $88.5 \%$ C16:0 (99\% total FA) for cows fed basal diets with soyhulls or whole cottonseed. That study reported that total FA digestibility of cows supplemented with $\mathrm{C} 16: 0(88.5 \%)$ ranged from $73.2 \%(2.25 \%)$ to $76.1 \%(0.75 \%)$. Moreover, that study showed that basal diets can affect the response to FA supplementation because only cows fed with a soyhull diet reduced the total FA digestibility with an 
increase in C16:0 dose. Therefore, further studies are needed to evaluate the effects high concentrations of specific SFA ( $>90 \%$ of a specific FA) on total FA digestion in dairy cows.

Data collection for the present work occurred in the first half of 2017, and thus only studies published before July 2017 were included in the database. Work published since that time includes efforts examining total FA digestion of palmitic acid supplements. Dairy cows fed fat supplements containing $\sim 85.1 \%$ of $\mathrm{C} 16: 0(1.5 \%$ of dietary DM) during peak, fresh, or both periods had total FA digestion varying from 72.3 to $72.7 \%$ at 25 to 67 d postpartum (de Souza et al., 2019a). That study reported $\mathrm{DCFA}_{\mathrm{TTa}}$ very similar to our results of 0.73 g/g FA ( $~ 85 \%$ of C16:0), which may be due to similar C16:0 concentrations $(\sim 85 \%)$. However, there was a tendency for an interaction between FA supplementation and time (DIM), and fresh cows (1 to 24 DIM) fed palmitic acid supplements had greater total FA digestion $(78.7 \%)$ than cows later in lactation $(\sim 72.6 \%$; de Souza et al., 2019a). This suggests a DMI effect that was not observed in our work.

Other factors have been observed to affect the digestibility of palmitic acid supplements, such as the form and individual FA composition. Cows fed palmitic acid TG supplement (78.6\% of C16:0, $1.5 \%$ of dietary DM) had lower total FA digestion $\left(\mathrm{DCFA}_{\mathrm{TTa}}=70.1 \%\right)$ than cows fed a free FA supplement of palmitic acid $(84.2 \%$ of C16:0, $\mathrm{DCFA}_{\mathrm{TTa}}=73.8 \%$; de Souza and Lock, 2019). Therefore, our palmitic acid supplement group $(\sim 85 \%$ of C16:0) had similar total FA digestion to cows fed a palmitic acid as a free FA supplement used in that study.

Feeding a FA supplement containing C16:0 plus $\mathrm{C} 18: 1$ (45\% of $\mathrm{C} 16: 0$ and $35 \%$ of $\mathrm{C} 18: 1$ cis-9; $1.5 \%$ of dietary $\mathrm{DM}$ ) to cows resulted in higher total FA digestion $\left(\mathrm{DCFA}_{\mathrm{TTa}}=79.4 \%\right)$ than cows fed only C16:0 (80\% of $\mathrm{C} 16: 0 ; \mathrm{DCFA}_{\mathrm{TTa}}=77.4 \%$ ) or both $\mathrm{C} 16: 0$ plus C18:0 (40\% of $\mathrm{C} 16: 0$ and $40 \%$ of $\mathrm{C} 18: 0, \mathrm{DCFA}_{\mathrm{TTa}}=$ $68.2 \%$ ). Moreover, that study reported that FA supply from basal diets can also interact with total FA digestion in dairy cows (de Souza et al., 2018). The results from that study is in accord with our work in which the palmitic acid group $(\sim 85 \%)$ had higher total FA digestion than the tallow triglyceride group (0.73 vs. $0.68 \mathrm{~g} / \mathrm{g} \mathrm{FA}$ ), which may be due to C18:0 concentration in animal fat sources.

Total FA digestion in dairy cows fed blends of C16:0 and C18:1 FA (C16:0-enriched FA and Ca-salts of palm FA) in animals with 3 different levels of milk production were reported (de Souza et al., 2019b). Cows fed supplements containing C16:0 ( $\sim 80 \%$ of $\mathrm{C} 16: 0)$ and cis-9 C18:1 (10\%) had total FA digestibilities of $76.5 \%$. That study described an interaction between milk production level and dietary ratio of C16:0 and C18:1 for milk yield. A total FA digestion of $77.5 \%$ was reported when cows were supplemented with C16:0 -enriched ( $81 \%$ of C16:0, $1.5 \%$ of dietary DM), and performance responses to palmitic acid supplement were more evident in multiparous cows than primiparous (de Souza and Lock, 2018a). Overall, those studies reported slightly greater total FA digestion for palmitic acid supplements (average $77 \%, \sim 80 \%$ of $\mathrm{C} 16: 0$ ) than our work $(0.73 \mathrm{~g} / \mathrm{g} \mathrm{FA}, \sim 85 \%$ of $\mathrm{C} 16: 0)$. Thus, additional refinement of the system developed herein may be possible as more information on the effects of individual FA accumulates.

In terms of ruminal digestion of FA, our study did not evaluate the metabolism of individual FA in the rumen, but a recent meta-analysis used data (104 publications, 437 treatment means) from dairy, beef, and ovine to develop and evaluate models for predicting individual FA flows from the rumen (Prado et al., 2019). Because the objective of our study was to evaluate total digestion of FA supplements, individual FA flows were not predicted in the present work.

Meta-analysis originated from medical science and is widely accepted in animal science for development of empirical nutrition models, which may help to understand a complex system or make predictions (Sauvant et al., 2019). The minimum number of studies required for a meta-analysis is a common question among scientists. Theoretically, meta-analysis is a re-analysis of data from studies or "the analysis of analyses" (Glass, 1976); consequently, a minimum of 2 studies might be accepted (Valentine et al., 2010, Pigott, 2012). Another aspect is the statistical power for meta-analysis, which was described in educational and social sciences. A power test is based on type I error and sample size, and this approach could indicate a minimum number of studies necessary to perform a meta-analysis, with a goal to have a given power considering the model adopted and assumptions (Valentine et al., 2010). Thus, the number of studies required is dependent on the form of the model. More model terms require more observations and range in observations. An inadequate number of observations or range in the observations will result in large errors of estimation for the parameters defined by that segment of the data. Thus, it is very difficult to define a priori the number of studies required; however, adequacy or lack of adequacy is obvious post-hoc.

As grouping was developed for the current work, based on a prior hypotheses and hypothesis testing, it was apparent that data were very limited (only 2 or 3 studies) for 3 groups of fat supplements: SFA-enriched tallow triglycerides, palmitic or stearic acid $>90 \%$, and palmitic acid $\sim 85 \%$ of $\mathrm{C} 16: 0$, and data for supplements with palmitic or stearic acid $>90 \%$ are still very 
limited. However, despite the limited data, the SE for the digestibility estimates for the first 2 groups are in line with the SE of the other groups, indicating that the data are fairly consistent. The SE for the palmitic acid $\sim 85 \%$ of C16:0 group was approximately double the SE for the other groups, and thus known with less certainty, and could likely be reduced with more observations. Despite the latter limitation, all estimates were derived with a high degree of certainty $(\mathrm{CV}<20 \%$ for all and $<10 \%$ for most), indicating the data were clearly adequate given the model.

Overall, cows that were fed with extensively saturated triglycerides had lower total FA digestion compared with those that were fed with partially protected FA rich in UFA, such as oilseeds and Ca-FA. Thus the level of saturation is a determinant of the digestibility of a fat source. As the composition of the FA also affects animal metabolism including milk production and composition, knowledge of the effect of FA composition and digestibility is important.

\section{CONCLUSIONS}

It is important to classify both feedstuffs and dietary sources of fat because the concentration of FA in feeds and its digestibility vary widely among groups. This large variation among groups may result in a significant bias if a single model is used across categories to predict both the total FA concentration in feeds or total FA digestibility. Therefore, models considering fat groups are recommended to improve the accuracy of the predictions. While fat supplements made with high concentration of a specific FA are limited, it is necessary to consider that interactions among FA from the fat supplements and basal diet may occur, increasing or reducing the total FA digestion of the cow. Ultimately, a model should be developed describing the effects of each FA on overall digestibility. Such an effort would negate the need to classify fat supplements and should lead to more accurate and robust estimates of individual FA supply, digestion, and metabolism. The current effort serves as a stepping stone to that larger goal and provides refined estimates of the individual FA supply to the animal for use in ration balancing as compared with prior models. This should result in more accurate and precise prediction of animal performance and milk composition.

\section{ACKNOWLEDGMENTS}

This study is part of the activities of the National Animal Nutrition Program (https://animalnutrition .org), a National Research Support Project (NRSP-9). The authors thank Tran et al. (2020) for the develop- ment of the feed library used in study 1 . The authors have not stated any conflicts of interest.

\section{REFERENCES}

AOAC International. 2012. Official Methods of Analysis. 19th ed. AOAC Int., Gaithersburg, MD.

Bainbridge, M., and J. Kraft. 2016. Lipid encapsulation provides insufficient total-tract digestibility to achieve an optimal transfer efficiency of fatty acids to milk fat. PLoS One 11:e0164700. https: //doi.org/10.1371/journal.pone.0164700.

Boerman, J. P., J. de Souza, and A. L. Lock. 2017. Milk production and nutrient digestibility responses to increasing levels of stearic acid supplementation of dairy cows. J. Dairy Sci. 100:2729-2738. https://doi.org/10.3168/jds.2016-12101.

Boerman, J. P., J. L. Firkins, N. R. St-Pierre, and A. L. Lock. 2015. Intestinal digestibility of long-chain fatty acids in lactating dairy cows: A meta-analysis and meta-regression. J. Dairy Sci. 98:88898903. https://doi.org/10.3168/jds.2015-9592.

Boufaïed, H., P. Y. Chouinard, G. F. Tremblay, H. V. Petit, R. Michaud, and G. Bélanger. 2003. Fatty acids in forages. I. Factors affecting concentrations. Can. J. Anim. Sci. 83:501-511. https:// doi.org/10.4141/A02-098.

Buccioni, A., M. Decandia, S. Minieri, G. Molle, and A. Cabiddu. 2012. Lipid metabolism in the rumen: New insights on lipolysis and biohydrogenation with an emphasis on the role of endogenous plant factors. Anim. Feed Sci. Technol. 174:1-25. https://doi.org/ 10.1016/j.anifeedsci.2012.02.009.

Chan, S. C., J. T. Huber, C. B. Theurer, Z. Wu, K. H. Chen, and J. M. Simas. 1997. Effects of supplemental fat and protein source on ruminal fermentation and nutrient flow to the duodenum in dairy cows. J. Dairy Sci. 80:152-159. https://doi.org/10.3168/jds.S0022 -0302(97)75922-8

Chouinard, P. Y., L. Corneau, W. R. Butler, D. E. Bauman, Y. Chilliard, and J. K. Drackley. 2001. Effect of dietary lipid source on conjugated linoleic acid concentrations in milk fat. J. Dairy Sci. 84:680-690. https://doi.org/10.3168/jds.S0022-0302(01)74522-5.

Clapham, W. M., J. G. Foster, J. P. S. Neel, and J. M. Fedders. 2005. Fatty acid composition of traditional and novel forages. J. Agric. Food Chem. 53:10068-10073. https://doi.org/10.1021/jf0517039.

de Souza, J., J. L. Garver, C. L. Preseault, and A. L. Lock. 2017. Short communication: Effects of prill size of a palmitic acid-enriched fat supplement on the yield of milk and milk components, and nutrient digestibility of dairy cows. J. Dairy Sci. 100:379-384. https:// doi.org/10.3168/jds.2016-11610.

de Souza, J., and A. L. Lock. 2018a. Long-term palmitic acid supplementation interacts with parity in lactating dairy cows: Production responses, nutrient digestibility, and energy partitioning. J. Dairy Sci. 101:3044-3056. https://doi.org/10.3168/jds.2017-13946.

de Souza, J., and A. L. Lock. 2018b. Short communication: Comparison of a palmitic acid-enriched triglyceride supplement and calcium salts of palm fatty acids supplement on production responses of dairy cows. J. Dairy Sci. 101:3110-3117. https://doi .org/10.3168/jds.2017-13560.

de Souza, J., and A. L. Lock. 2019. Milk production and nutrient digestibility responses to triglyceride or fatty acid supplements enriched in palmitic acid. J. Dairy Sci. 102:4155-4164. https://doi .org/10.3168/jds.2018-15690.

de Souza, J., C. L. Preseault, and A. L. Lock. 2018. Altering the ratio of dietary palmitic, stearic, and oleic acids in diets with or without whole cottonseed affects nutrient digestibility, energy partitioning, and production responses of dairy cows. J. Dairy Sci. 101:172-185. https://doi.org/10.3168/jds.2017-13460.

de Souza, J., C. Strieder-Barboza, G. A. Contreras, and A. L. Lock. 2019a. Effects of timing of palmitic acid supplementation during early lactation on nutrient digestibility, energy balance, and metabolism of dairy cows. J. Dairy Sci. 102:274-287. https://doi.org/ 10.3168/jds.2018-14977.

de Souza, J., N. R. St-Pierre, and A. L. Lock. 2019b. Altering the ratio of dietary C16:0 and cis-9 C18:1 interacts with production level in 
dairy cows: Effects on production responses and energy partitioning. J. Dairy Sci. 102:9842-9856. https://doi.org/10.3168/jds.2019 $-16374$.

Dewhurst, R., and King.. 1998. Effects of extended wilting, shading and chemical additives on the fatty acids in laboratory grass silages. Grass Forage Sci. 53:219-224. https://doi.org/10.1046/j .1365-2494.1998.00130.x.

Dewhurst, R. J., N. D. Scollan, S. J. Youell, J. K. S. Tweed, and M. O. Humphreys. 2001. Influence of species, cutting date and cutting interval on the fatty acid composition of grasses. Grass Forage Sci. 56:68-74. https://doi.org/10.1046/j.1365-2494.2001.00247.x.

Drackley, J. K. 2004. Overview of fat digestion and metabolism in dairy cows. University of Illinois, Urbana. Accessed Nov. 4, 2019. http:/ /livestocktrail.illinois.edu/uploads/dairynet/papers/Overview\%20 of $\% 20$ Fats $\% 2004$.pdf.

Drackley, J. K., and J. P. Elliott. 1993. Milk composition, ruminal characteristics, and nutrient utilization in dairy cows fed partially hydrogenated tallow. J. Dairy Sci. 76:183-196. https://doi.org/10 .3168/jds.S0022-0302(93)77337-3.

Drackley, J. K., D. E. Grum, G. C. McCoy, and T. H. Klusmeyer. 1994. Comparison of three methods for incorporation of liquid fat into diets for lactating dairy cows. J. Dairy Sci. 77:1386-1398. https://doi.org/10.3168/jds.S0022-0302(94)77077-6.

Eastridge, M. L., and J. L. Firkins. 1991. Feeding hydrogenated fatty acids and triglycerides to lactating dairy cows. J. Dairy Sci. 74:2610-2616. https://doi.org/10.3168/jds.S0022-0302(91)78439 -7 .

Elliott, J. P., J. K. Drackley, and D. J. Weigel. 1996. Digestibility and effects of hydrogenated palm fatty acid distillate in lactating dairy cows. J. Dairy Sci. 79:1031-1039. https://doi.org/10.3168/ jds.S0022-0302(96)76456-1.

Espindola, M. S., E. J. DePeters, J. G. Fadel, R. A. Zinn, and H. Perez-Monti. 1997. Effects on nutrient digestion of wheat processing and method of tallow addition to the diets of lactating dairy cows. J. Dairy Sci. 80:1160-1171. https://doi.org/10.3168/jds .S0022-0302(97)76043-0.

Firkins, J. L., and M. L. Eastridge. 1994. Assessment of the effects of iodine value on fatty acid digestibility, feed intake, and milk production. J. Dairy Sci. 77:2357-2366. https://doi.org/10.3168/ jds.S0022-0302(94)77178-2.

Firkins, J. L., M. L. Eastridge, N. R. St-Pierre, and S. M. Noftsger. 2001. Effects of grain variability and processing on starch utilization by lactating dairy cattle. J. Anim. Sci. 79(E-Suppl):E218E238. https://doi.org/10.2527/jas2001.79E-SupplE218x.

Fuentes, M. C., S. Calsamiglia, P. W. Cardozo, and B. Vlaeminck. 2009. Effect of $\mathrm{pH}$ and level of concentrate in the diet on the production of biohydrogenation intermediates in a dual-flow continuous culture. J. Dairy Sci. 92:4456-4466. https://doi.org/10.3168/ jds.2008-1722.

Glass, G. V. 1976. Primary, secondary, and meta-analysis of research. Educ. Res. 5:3-8. https://doi.org/10.3102/0013189X005010003.

Glasser, F., M. Doreau, G. Maxin, and R. Baumont. 2013. Fat and fatty acid content and composition of forages: A meta-analysis. Anim. Feed Sci. Technol. 185:19-34. https://doi.org/10.1016/j .anifeedsci.2013.06.010

Glasser, F., A. Ferlay, and Y. Chilliard. 2008a. Oilseed lipid supplements and fatty acid composition of cow milk: A meta-analysis. J. Dairy Sci. 91:4687-4703. https://doi.org/10.3168/jds.2008-0987.

Glasser, F., P. Schmidely, D. Sauvant, and M. Doreau. 2008b. Digestion of fatty acids in ruminants: A meta-analysis of flows and variation factors: 2. C18 fatty acids. Animal 2:691-704. https:// doi.org/10.1017/S1751731108002036.

Harfoot, C. G. 1981. Lipid metabolism in the rumen. Pages 21-55 in Lipid Metabolism in Ruminant Animals. W. W. Christie, ed. Pergamon, Ayr, Scotland.

Harvatine, K. J., and M. S. Allen. 2006. Effects of fatty acid supplements on ruminal and total tract nutrient digestion in lactating dairy cows. J. Dairy Sci. 89:1092-1103. https://doi.org/10.3168/ jds.S0022-0302(06)72177-4.

Higgs, R. J., L. E. Chase, D. A. Ross, and M. E. Van Amburgh. 2015. Updating the Cornell Net Carbohydrate and Protein System feed library and analyzing model sensitivity to feed inputs. J. Dairy Sci. 98:6340-6360. https://doi.org/10.3168/jds.2015-9379.

Jenkins, T. C. 1994. Regulation of lipid metabolism in the rumen. J. Nutr. 124(suppl_8):1372S-1376S. https://doi.org/10.1093/jn/124 .suppl_8.1372S

Jenkins, T. C., and B. F. Jenny. 1989. Effect of hydrogenated fat on feed intake, nutrient digestion, and lactation performance of dairy cows. J. Dairy Sci. 72:2316-2324. https://doi.org/10.3168/ jds.S0022-0302(89)79363-2.

Kalscheur, K. F., B. B. Teter, L. S. Piperova, and R. A. Erdman. 1997. Effect of fat source on duodenal flow of trans-C18:1 fatty acids and milk fat production in dairy cows. J. Dairy Sci. 80:2115-2126. https://doi.org/10.3168/jds.S0022-0302(97)76157-5.

Khan, N. A., T. A. Tewoldebrhan, R. L. Zom, J. W. Cone, and W. H. Hendriks. 2012. Effect of corn silage harvest maturity and concentrate type on milk fatty acid composition of dairy cows. J. Dairy Sci. 95:1472-1483. https://doi.org/10.3168/jds.2011-4701.

Lin, L. 1989. A concordance correlation coefficient to evaluate reproducibility. Biometrics 45:255-268. https://doi.org/10.2307/ 2532051.

Lock, A. L., and J. de Souza. 2017. Update on fatty acid digestion and metabolism and impacts on milk production. In Proc. Tri-State Dairy Nutrition Conference. Accessed Oct. 4, 2019. https://docs .wixstatic.com/ugd/36a444_6701906cd64040cebee27d07e97aaaff .pdf.

Lock, A. L., K. J. Harvatine, J. K. Drackley, and D. E. Bauman. 2006. Concepts in fat and fatty acid digestion in ruminants. Proc. Intermountain Nutr. Conf.:85-100.

Lock, A. L., C. L. Preseault, J. E. Rico, K. E. DeLand, and M. S. Allen. 2013. Feeding a C16:0-enriched fat supplement increased the yield of milk fat and improved conversion of feed to milk. J. Dairy Sci. 96:6650-6659. https://doi.org/10.3168/jds.2013-6892.

Loften, J. R., J. G. Linn, J. K. Drackley, T. C. Jenkins, C. G. Soderholm, and A. F. Kertz. 2014. Invited review: Palmitic and stearic acid metabolism in lactating dairy cows. J. Dairy Sci. 97:46614674. https://doi.org/10.3168/jds.2014-7919.

Loor, J. J., K. Ueda, A. Ferlay, Y. Chilliard, and M. Doreau. 2004. Biohydrogenation, duodenal flow, and intestinal digestibility of trans fatty acids and conjugated linoleic acids in response to dietary forage:concentrate ratio and linseed oil in dairy cows. J. Dairy Sci. 87:2472-2485. https://doi.org/10.3168/jds.S0022-0302(04)73372 $-\mathrm{X}$.

Moallem, U. 2018. Invited review: Roles of dietary n-3 fatty acids in performance, milk fat composition, and reproductive and immune systems in dairy cattle. J. Dairy Sci. 101:8641-8661. https://doi .org/10.3168/jds.2018-14772.

NRC (National Research Council). 2001. Nutrient Requirements of Dairy Cattle. 7th rev. ed. Natl. Acad. Sci., Washington, DC.

Oldick, B. S., and J. L. Firkins. 2000. Effects of degree of fat saturation on fiber digestion and microbial protein synthesis when diets are fed twelve times daily. J. Anim. Sci. 78:2412-2420. https://doi .org/10.2527/2000.7892412x.

Palmquist, D. L. 1991. Influence of source and amount of dietary fat on digestibility in lactating cows. J. Dairy Sci. 74:1354-1360. https://doi.org/10.3168/jds.S0022-0302(91)78290-8.

Palmquist, D. L., and T. C. Jenkins. 1980. Fat in lactation rations. J. Dairy Sci. 63:1-14. https://doi.org/10.3168/jds.S0022 $-0302(80) 82881-5$.

Palmquist, D. L., and T. C. Jenkins. 2003. Challenges with fats and fatty acid methods. J. Anim. Sci. 81:3250-3254. https://doi.org/ $10.2527 / 2003.81123250 \mathrm{x}$.

Palmquist, D. L., and T. C. Jenkins. 2017. A 100-Year Review: Fat feeding of dairy cows. J. Dairy Sci. 100:10061-10077. https://doi .org/10.3168/jds.2017-12924.

Palmquist, D. L., M. R. Weisbjerg, and T. Hvelplund. 1993. Ruminal, intestinal, and total digestibilities of nutrients in cows fed diets high in fat and undegradable protein. J. Dairy Sci. 76:1353-1364. https://doi.org/10.3168/jds.S0022-0302(93)77466-4.

Pigott, T. D. 2012. Advances in meta-analysis. Springer Science \& Business Media, New York, NY. 
Prado, L. A., A. Ferlay, P. Nozière, and P. Schmidely. 2019. Predicting duodenal flows and absorption of fatty acids from dietary characteristics in ovine and bovine species: a meta-analysis approach. Animal 13:727-739. https://doi.org/10.1017/S1751731118001982.

R Core Team. 2018. A language and environment for statistical computing. Version 3.5.1. R. Foundation for Statistical Computing, Vienna, Austria.

Rafiee-Yarandi, H., G. R. Ghorbani, M. Alikhani, A. Sadeghi-Sefidmazgi, and J. K. Drackley. 2016. A comparison of the effect of soybeans roasted at different temperatures versus calcium salts of fatty acids on performance and milk fatty acid composition of mid-lactation Holstein cows. J. Dairy Sci. 99:5422-5435. https:// doi.org/10.3168/jds.2015-10546.

Rico, J. E., J. de Souza, M. S. Allen, and A. L. Lock. 2017. Nutrient digestibility and milk production responses to increasing levels of palmitic acid supplementation vary in cows receiving diets with or without whole cottonseed. J. Anim. Sci. 95:436-446.

Roman-Garcia, Y., R. R. White, and J. L. Firkins. 2016. Meta-analysis of postruminal microbial nitrogen flows in dairy cattle. I. Derivation of equations. J. Dairy Sci. 99:7918-7931. https://doi.org/10 $.3168 /$ jds.2015-10661.

Santos, F. A. P., J. E. P. Santos, C. B. Theurer, and J. T. Huber. 1998. Effects of rumen-undegradable protein on dairy cow performance: A 12-year literature review. J. Dairy Sci. 81:3182-3213. https://doi .org/10.3168/jds.S0022-0302(98)75884-9.

Sauvant, D., M. Letourneau-Montminy, P. Schmidely, M. Boval, C. Loncke, and J. Daniel. 2019. Use and misuse of meta-analysis in Animal Science. In hal-02181827. Accessed Jan. 30, 2020. https:// hal.archives-ouvertes.fr/hal-02181827.

St-Pierre, N. R. 2001. Invited review: Integrating quantitative findings from multiple studies using mixed model methodology. J. Dairy Sci. 84:741-755. https://doi.org/10.3168/jds.S0022-0302(01)74530 -4 .

St-Pierre, N. R., and W. P. Weiss. 2015. Partitioning variation in nutrient composition data of common feeds and mixed diets on commercial dairy farms. J. Dairy Sci. 98:5004-5015. https://doi .org/10.3168/jds.2015-9431.

Sukhija, P. S., and D. L. Palmquist. 1990. Dissociation of calcium soaps of long-chain fatty acids in rumen fluid. J. Dairy Sci. 73:1784-1787. https://doi.org/10.3168/jds.S0022-0302(90)78858-3.
Tran, H., A. Schlageter-Tello, A. Caprez, P. S. Miller, M. B. Hall, W. P. Weiss, and P. J. Kononoff. 2020. Development of feed composition tables using a statistical screening procedure. J. Dairy Sci. 103:3786-3803. https://doi.org/10.3168/jds.2019-16702.

Valentine, J. C., T. D. Pigott, and H. R. Rothstein. 2010. How many studies do you need?: A primer on statistical power for meta-analysis. J. Educ. Behav. Stat. 35:215-247. https://doi.org/10.3102/ 1076998609346961.

Van Amburgh, M. E., E. A. Collao-Saenz, R. J. Higgs, D. A. Ross, E. B. Recktenwald, E. Raffrenato, L. E. Chase, T. R. Overton, J. K Mills, and A. Foskolos. 2015. The Cornell Net Carbohydrate and Protein System: Updates to the model and evaluation of version 6.5. J. Dairy Sci. 98:6361-6380. https://doi.org/10.3168/jds.2015 $-9378$.

Weld, K. A., and L. E. Armentano. 2017. The effects of adding fat to diets of lactating dairy cows on total-tract neutral detergent fiber digestibility: A meta-analysis. J. Dairy Sci. 100:1766-1779. https:/ /doi.org/10.3168/jds.2016-11500.

Wu, Z., O. A. Ohajuruka, and D. L. Palmquist. 1991. Ruminal synthesis, biohydrogenation, and digestibility of fatty acids by dairy cows. J. Dairy Sci. 74:3025-3034. https://doi.org/10.3168/jds .S0022-0302(91)78488-9.

Zened, A., A. Troegeler-Meynadier, M. C. Nicot, S. Combes, L. Cauquil, Y. Farizon, and F. Enjalbert. 2011. Starch and oil in the donor cow diet and starch in substrate differently affect the in vitro ruminal biohydrogenation of linoleic and linolenic acids. J. Dairy Sci. 94:5634-5645. https://doi.org/10.3168/jds.2011-4491.

\section{ORCIDS}

V. L. Daley ํㅜ https://orcid.org/0000-0003-0238-7408

L. E. Armentano (i) https://orcid.org/0000-0002-5113-8240

P. J. Kononoff $\odot$ https://orcid.org/0000-0001-6069-2174

M. D. Hanigan @ \ttps://orcid.org/0000-0002-5639-9677 